\title{
Experimental study on kinematics of sea ice floes in regular waves
}

(1)

(3)

\author{
David J. McGovern, Wei Bai* \\ Department of Civil and Environmental Engineering, National University of Singapore, Kent Ridge, Singapore 117576, \\ Singapore
}

\section{Abstract}

Ice floes in severe Arctic seas can gain significant kinetic energy. Such a fast moving floe presents a significant impact threat to offshore structures. Most attention to date has focused on glacial icebergs, which are now reasonably well understood; there appears a lack of knowledge in the case of isolated sea ice floes. To address this an experimental investigation of the relationships of the motion response of floes to the floe and wave characteristics was conducted. Of greatest importance to impact force calculations are the heave and surge motions, as well as the velocity and acceleration of a floe in waves. The tested variables included a wide range of regular waves with a variety of floe model shapes and sizes. The results showed that scale effect, floe size, floe orientation and surface roughness did not affect the heave and surge motion, and the motion observed was notably different to glacial icebergs. Wavelength affected motion the most; all models displayed fluid particle-like motion paths at $\lambda$ between 3.3 and 5 times their characteristic lengths and the majority of scatter between different floe geometries in motion response was confined $\lambda / L_{c}<8$. Floe thickness also had a dramatic affect on heave and surge, with thicker models experiencing significant resonances. Drift velocity matched Stokes drift quite well, though the larger models appeared to show greater than predicted drift velocities. Maximum velocities did not generally exceed particle velocity, but remained $>0.7 V_{P}$ and for surge and $>0.8 V_{P}$ heave at $\lambda / L_{c} \geq 5$. Such high velocities at shorter $\lambda$ suggest that a more conservative design approach may be necessary. An extrapolation of these velocities leads to a conclusion that prototype ice floes can obtain kinetic energies of $10^{6}$ $\mathrm{J}$ in certain conditions.

Key words: Ice Floe; Kinematics; Floe Drift; Floe Velocity; Experimental Study

\footnotetext{
* Corresponding author. E-mail address: w.bai@nus.edu.sg (W. Bai).
} 


\section{Introduction}

Trends in Arctic sea ice coverage indicate that the Arctic Ocean may be free of ice for short periods in the

5 summer by 2040 or earlier (e.g. Turner and Marshall, 2011, and ACIA, 2004). For shipping, seasonal navigability of the North West Passage and Northern Sea Route would reduce the maritime journey between the Atlantic and Pacific dramatically. As such, tans-arctic shipping is expected to increase rapidly in the next few decades (DNV, 2010). In addition, USGS survey (USGS, 2008) approximated that $13 \%$ and $30 \%$ of the world's current undiscovered oil and gas respectively is located in the Arctic and adjacent cold regions. Reducing ice coverage opens up the possibilities for seasonal drilling.

Pack ice is often found close to and in contact with arctic shipping and offshore drilling structures due to the melting process, wave action, and ice management operations. In low concentrations a single isolated ice floe may be a common occurrence in summer months and warmer climates (Timco, 2011). Such a floe, if small enough with respect to the dominant wavelength, may be quite sensitive to severe seas.

The problem falls into the field of freely floating thin bodies, a subject that has been intensively researched to date due to its relevance to very large floating platforms (VLFPs) and sea ice. Rigid floating bodies (i.e., not compliant with the free surface) have been the subject of rigorous research for over a century (Wehausen, 1971). Much of this work centres on numerical solutions of the kinematic response of rigid bodies in waves. For the case of sea-ice floes, see for example two comprehensive reviews by Squire et al. (1995) and Squire, (2007). Within these reviews it is clear that there is a wealth of research on the interaction of ocean waves with the Marginal Ice Zone (MIZ). The MIZ is the region where ocean waves and the ice sheet interact, and is characterised by a large area of broken ice. Ice in the MIZ is recognised as being compliant; i.e., sensitive to hydroelasticity. This flexure has received much attention recently, (Masson and LeBlond, 1989, Meylan and Squire, 1994, 1996, Meylan, 2002, Wang and Meylan, 2004, Williams and Squire 2006, to name but a few). Sakai and Hanai, (2002) conducted two dimensional experiments on the vertical displacement of elastic floes modelled from polyethylene plates. They used their data to determine an empirical dispersion relation for flexural gravity waves travelling in continuous ice-covered seas. Most recently, Montiel et al. (2013a, b) conducted a two-part experiment looking into the flexure of very thin single and pairs of circular plates in regular waves in the lab (2013a) and numerically (2013b). The thin plate was modelled out of compliant PVC 
and restricted to vertical motion only. With a maximum plate thickness of $1 \mathrm{~cm}$ and a radius of $142 \mathrm{~cm}$ these models scale to very large thin floes in the prototype. The regular waves were of small amplitude compared with wavelength (small wave steepness) and the circular disc was large making diffraction effects significant. Such very large floes (that is much greater than the incident wavelength) behave similarly to VLFPs in that their response involves significant flexure of the floe. The hydroelasticity of these large ice floes is important for their fracture and break up into smaller floes (e.g. Toyota et al. 2011 and Squire 2007). It is the propagation of flexural-gravity waves through the ice sheet that causes it to break up into sizes that are equivalent to the dominant wavelengths. This is an important feature of the MIZ and there is significant literature on the subject (see reviews of Squire et al. 1996, Squire 2007 and Squire 2011) that relates the interaction of waves with the ice sheet as the primary cause of the creation of the MIZ.

Once created, smaller floes from the MIZ, as well as very large detached floes may drift into the open ocean under wave driven second order drift forces, as well as wind and current induced drift causing them to travel vast distances (Timco, 2011). The floes may still be many km’s in length, but will be found in all different sizes down to small floes that will be sensitive to $1^{\text {st }}$ order motions from wave forcing. Such small floes in the MIZ are sensitive to full six degrees of freedom of motion (Frankenstein et al. 2001) so it is reasonable to assume that this would also be the case in the open ocean, where wave heights are not damped by the MIZ. Indeed such motions have been measured in the field on isolated glacial ice bergs of a variety of sizes from many km’s in length (Kristensen et al. 1982, Wadhams et al. 1983), to small bergy bits (Lever and Diemand 1985, Lever et al. 1991). In the lab, icebergs much smaller than the dominant wavelengths have been shown to behave as water particles, thereby gaining significant kinetic energy (Murray et al. 1983, Arunachalam et al. 1987, Lever et al. 1988a, Lever et al. 1990). Murray et al. (1983) conducted a qualitative analysis to determine the maximum instantaneous surge and drift velocities attained by spherical, cylindrical and cubic paraffin wax iceberg models in regular waves. The models were found to attain near fluid particle velocity when the ratio of wavelength $\lambda$ with characteristic ice length $L_{c}$ (given here as the longest length along the floe edge) was $\geq 3$, below which the velocity achieved is much reduced. Arunachalam et al. (1987) performed a study to estimate the first order surge and heave motions of an iceberg in regular waves. Focusing on draft ( $d r$ ) they observed for $\lambda / L_{c}<3.3, d r / d=0.1$ (where $d$ is the water depth) the ice models behaved close to fluid particles. Surge and heave were reduced as $d r / d$ increased towards unity and heave amplitude $\approx$ wave amplitude for $L_{c} \approx 1 / 10^{\text {th }} \lambda$. Both Arunachalam et al. (1987) and Murray et al. (1983) observed 
resonance heave motions at various conditions for different models. Lever et al. (1988a) found particle like motion and velocities for $L_{c} / \lambda>12-13$, as well as significant heave resonances. Lever et al. (1990) completed a study of the influence of the iceberg shape on its motion, finding large scatter in recorded motion depending on shape.

It is reasonable to assume that an isolated floe that is small enough may also be subject to significant wave forcing. Furthermore, while the flexural response of ice floes is a very important mechanical property as it is their hydroelasticity in waves that pays a major role in the break-up of large floes into small ones, once floes are much smaller than the dominant wavelengths, bending becomes negligible (e.g. Meylan and Squire 1994, 1996). Here the main dampening response of the floe will be the generation of outgoing waves in the free surface analogous to the kinematic response of a rigid body (Squire 2007). This is the crux of our investigation; what is the kinematic response of a floe whose length is much smaller than the dominant wavelength? Such an isolated floe impact with an offshore structure is a very common of ice-structure interaction event (Timco, 2011). He reviews field measurements of a variety of drifting floe-structure impact events with flow sizes ranging from km's to several meters in size. A simple linear regression of the data defined a remarkably sturdy relationship between floe kinetic energy and impact force from very small to very large floes. The overall conclusion appears solid for the case of floes drifting towards obstacles. But what about the case of small floes under the action of severe waves in the open ocean well away from the MIZ? To date, despite the numerous numerical treatments, and to a lesser extent, field and laboratory investigations of floe response (i.e. attenuation, dispersion and scattering of, flexural response and break up) in waves in the MIZ there appears, to the authors' knowledge, no specific treatise of the kinematic response of isolated small floes in severe seas. Because sea ice has specific density and draft characteristics, it needs to be treated differently than other rigid relatively flat floating bodies in waves (for example Wehausen, 1971).

We are also interested in the second order drift velocity $\left(V_{d}\right)$ of these small floes, as this will help define point to point travel times, trajectories and impact force. Good progress has been made in the determination of $V_{d}$ characteristics and velocity for pancake ice (Frankenstein and Shen, 1997), while Harms (1987) presented a series of two-dimensional experiments examining the $V_{d}$ of ice floes in regular waves. $V_{d}$ was shown to be sensitive to the ratio of wave period $T$ to ice mass roll period $T_{r}$, wave steepness and $L_{c}$, with the greatest $V_{d}$ when $T>>T_{r}$. Wake et al. (1987) studied the particular case of floes of $L_{c}>>\lambda$. Their results indicated that width of floe appeared to have no influence on $V_{d}$, while floe thickness $b$ appeared to have 
more influence than $L_{c}$ on $V_{d}$; an increase in $b$ lowered both the terminal drift velocity and the time taken to reach it. An asymptotic limit to terminal $V_{d}$ was observed at $L_{c} / b>16$. For large draft cylinders representing icebergs, wave induced drift into offshore structures was studied by Isaacson and McTaggart, (1990). Laboratory flume experiments of small isolated bodies of limited oval and square shapes in regular waves are presented by Huang et al. (2011) who find some discrepancy between theoretical Stokes drift and measured drift, with drift appearing to be greater than predicted. Current induced drift of large floes in the laboratory was investigated by Frederking and Timco, (2000) and numerical studies of wave induced drift of small rigid bodies and thin plates were presented by Shen and Zhong, (2001) and Grotmaarck and Meylan, (2006) respectively. Grotmaarck and Meylan (2006) showed mathematically that the conclusion of Shen and Zhong (2001) that $V_{d}$ was dependent on initial body position and velocity to be false. Notwithstanding these investigations, we believe that further practical data specific to isolated small floes will further aid validation of numerical models, and in particular shed insight to the parametric relationships between drift velocity and floe and wave characteristics. We believe this will be of practical use to improve predictive theories.

Thus we propose the following physical investigation of the functional relationships between isolated small ice floe characteristics, the forcing wave and the resulting kinematic response of the floe for both its first order motion and velocity, as well as second order drift velocity. In order to achieve this, the motion response in regular waves is analysed. Design codes are vague in their description of ice velocity: for example, the statement in ISO 19906 (ISO 2010) suggests without reference: “...Pieces of ice with maximum dimension less than $1 / 15$ of the incident wavelength (i.e. $\lambda / L_{c} \geq 15$ ) can be conservatively assumed to follow water particle velocity...” Such knowledge should also help improve current industry codes and practices (Palmer, 2011).

\section{Experimental method}

The wave flume used in the present study is located at the National University of Singapore Hydraulic Engineering Laboratory. The flume is $2 \mathrm{~m}$ wide and $32 \mathrm{~m}$ long with a piston type wave paddle generating regular waves propagating from right to left as in Figure 1. Time-series free surface elevation was measured using calibrated resistance-type wave probes (accuracy $+/-0.1 \mathrm{~mm}$ ) situated $8.8 \mathrm{~m}$ downstream of the wave paddle with a second pair positioned downstream of the test section. An effective absorption beach was 
located at the end of the flume. Extensive testing during the construction of the flume showed that the beach reflects $<5 \%$ of incident wave height. To quantify reflection in the current set-up and wave conditions, a series of tests were conducted to determine the reflected wave height. This was done using a single wave probe to take measurements at eight locations along the flume within one wavelength $\lambda$ (see for example, Hughes 1993). The results showed the reflected wave was $<5 \%$ in all wave conditions tested. For $\lambda \leq 100$ $\mathrm{cm}$, the wave celerity $c$ was too slow for reflections to return to the test section within the period of one run. The time for re-reflections off the wave paddle to reach the test section was also too slow to be an issue in any test. Therefore, the $H$ referred to in this study is the value measured by the upstream probes.

The floe models were constructed from paraffin wax of density $\rho=890 \mathrm{~kg} \mathrm{~m}^{-3}$. The measured density of sea ice from the reported values in Timco and Frederking, (1996) varies between $840-910 \mathrm{~kg} \mathrm{~m}^{-3}$ for first year ice and 720 - $910 \mathrm{~kg} \mathrm{~m}^{-3}$ for multiyear ice. Field measurements of individual floe thickness $b$ give a range of $b=2 \mathrm{~m}$ to $6 \mathrm{~m}$ for first and multiyear floes respectively (for example, Shirasawa et al. 2009, Kwok and Rothrock, 2009 and Xie et al. 2011). By focusing on thick multiyear ice, where $b$ is $\geq 2.5$, we assume the floe behaves as a rigid body, and ignore its flexural response. We justify this in the following. The flexural response of a floe is related to $b, \lambda / L_{c}$, internal brine and gas content, and homogeneity of their structure (e.g., Cole, 1998 and Timco and Weeks, 2010). We assume the floe density distribution is homogeneous. According to Meylan and Squire (1994), small floes $1 \mathrm{~m}$ thick and $<80 \mathrm{~m}$ in length do not bend significantly regardless of wavelength. Additionally Meylan and Squire (1996) observe negligible flexure when $L_{c}=50$ $\mathrm{m}$ and $b=0.5 \mathrm{~m}$, which decreases further still as $b$ increased to $5 \mathrm{~m}$. An experimental investigation using real ice by Frankenstein and Shen (1997) found no bending in their $\sim 2 \mathrm{~cm}$ thick pancake ice in wave periods $T$ from $1.71-2.73$ as they were too thick. While $T$ values in this study are shorter, the maximum prototype $L_{c}=30 \mathrm{~m}, \lambda / L_{c}>1$ and $b \geq 2.5 \mathrm{~m}$ mean that the flexural response of the floe will be negligible. Indeed, it is more computationally efficient for numerical models of small ice floes to be modelled as rigid bodies (Meylan, 2002). Thus we choose paraffin wax as it fits these requirements and has distinct advantages in its successful use in similar studies of glacial ice (see Lever, et al. 1988a, Lever, et al. 1988b, Lever, et al. 1990, Lever et al. 1991, and Murray et al. 1983), and its ease of procurement and moulding. By modelling the floe as rigid, this experimental data is more suited to validation with numerical methods such as Masson and LeBlond (1989) and Meylan (2002). 
Time-series model heave and surge motion was recorded using a PhaseSpace Improv motion tracking system. This consisted of 8 CCD cameras mounted on a frame around the test section supported by the flume walls (Figure 2a) connected to a controlling server computer and PC that were positioned outside the flume. The cameras tracked 'Stylus' LEDs that measured $5 \mathrm{~cm}$ long by $2 \mathrm{~cm}$ wide by $0.8 \mathrm{~cm}$ thick and weigh $13 \mathrm{~g}$. The LEDs were positioned at equidistant points from each corner of the ice model and on plastic stands (8.5 g) to raise them out of reach of overtopping water. The LEDs and stands were placed streamline normal to the incident wave thus presenting only $~ 0.3 \mathrm{~cm}$ profile to the oncoming wave (Figure 2c-d).

The system was calibrated using a calibration wand on which LEDs are fixed at known distances apart. The cameras are able to resolve the LED to $0.1 \mathrm{~mm}$ at a distance of $5 \mathrm{~m}$, meaning for the current set-up the resolution is at least equal to $0.1 \mathrm{~mm}$. The accuracy of the system is rated at $1 \%$ of the distance between the cameras and the measured LED. In order to assess the accuracy of the system and the calibration independently, four LEDs were positioned on a frame which was then translated and rotated by known amounts. The results indicated an error of $<2 \%$ of the measured distance in our set-up. As the position information is recorded directly by the cameras it was felt that as the high frequency capture rate $(240 \mathrm{~Hz})$ was well in excess of wave period $(T<2 \mathrm{~s})$, it was unnecessary to conduct dynamic displacement tests of the systems accuracy. Quasi-quantitative confirmation of the Phasespace system accuracy was achieved by analysing video image stills of the floe model motion across a measuring grid placed over the viewing window of the flume test section. The displacements calculated from the video were in good agreement to those recorded by the camera system.

Figure 1. Schematic diagram of the experimental setup.

Figure 2. (a) Image of the PhaseSpace camera set-up; (b) image of a floe model; (c) two Stylus LED units and stands and (d) the model with the LEDs units during a test.

\subsection{Ice model and wave scaling}

To accurately reproduce free surface effects in the laboratory geometric, kinematic and dynamic similarity with the prototype must be preserved. Complete similitude requires that the Froude number $\left(F r=V^{2} / g L_{c}\right.$ 
1 where $V$ is the fluid or body velocity and $g$ is acceleration due to gravity) and Reynolds number $\left(R e=V L_{c} / v\right.$,

2 where $v$ is the kinematic viscosity of the fluid) are the same in both model and prototype. However, concurrent

3 similitude of $F r$ and $R e$ in a single model is not possible as the use of water results in an under scaling of

$8 \quad V_{p}=\sqrt{l} V_{m}$

$9 \quad T_{p}=\sqrt{l} T_{m}$.

$L_{p}=l L_{m}$ fluid viscosity. Fr similitude is normally chosen in free surface modelling of non-breaking waves, as gravity is the dominant restoring force in both the model and prototype. The $F r$ relationships between model $(m)$ and prototype $(p)$ are given as:

The scale factor $l$ was set at 1:100. The water depth $d$ was $0.9 \mathrm{~m}$ and the $T$ ranged between 0.5 and $1.5 \mathrm{~s}$ relating to a $5-15 \mathrm{~s}$ prototype $T$ in $d=90 \mathrm{~m}$. $\lambda$ is determined from the dispersion equation of linear wave theory for intermediate water, which reduces to $\lambda=1.56 T^{2}$ for waves in deep water. The standard prototype dimensions used in the present study are a $30 \mathrm{~m}$ by $30 \mathrm{~m}$ square shaped floe with $b$ of $5 \mathrm{~m}$, relating to a plausible multiyear prototype floe $b$. This scales to a $30 \mathrm{~cm}$ by $30 \mathrm{~cm}$ by $5 \mathrm{~cm}$ model in the flume.

\subsection{Test conditions}

In regular waves, the main variables that will dictate the kinematics of a floating body are $\lambda$ and $H$. To investigate the influence of $\lambda$ and $H$ on the ice model motion, tests were conducted for a range of $\lambda / L_{c}$ and a range of wave steepness's $(H / \lambda)$. Re number will, however, affect the boundary layer characteristics of the floe model, and so its dissimilitude between the model and prototype requires investigation. Where $H / \lambda$ and $d$ is constant, the motion of the floe model should only be influenced by $\lambda / L_{c}$, thus if $R e$ dissimilitude does not influence the motion response the Response Amplitude Operator (RAO) should plot on the same curve regardless of $\mathrm{Fr}$ scale factor. Therefore, three models of the exact same shape (square) but different sizes were constructed, thereby creating identical test conditions at different $F r$ length scales. These included squares $30 \mathrm{~cm}$ long by $5 \mathrm{~cm}$ thick, $24 \mathrm{~cm}$ long by $4 \mathrm{~cm}$ thick and $20 \mathrm{~cm}$ long by $3.3 \mathrm{~cm}$ thick (named Square ( $\left.L_{c} 30, b 5\right)$, Square $\left(L_{c} 24, b 4\right)$ and Square $\left(L_{c} 20, b 3.3\right)$ respectively). These models correspond to $F r$ scale 
factors of 100:1, 125:1 and 150:1 respectively. The corresponding prototype/model Re ratio is according to

$3 \quad \operatorname{Re}_{p}=l \sqrt{l} \operatorname{Re}_{m}$. Equation (4) 1000, 1400 and 1800.

To investigate the functional relationships that may exist between $\lambda, H$ and the shape, size and roughness $r$ of the floe, a variety of models were constructed (Table 1$)$. The standard floe model was square $\left(L_{c} 30, b\right.$ 5), which is also shown in Figure 2b. Two $30 \mathrm{~cm}$ long squares of $b=2.5$ and $7.5 \mathrm{~cm}$ (Square $\left(L_{c} 30, b 7.5\right)$ and Square ( $L_{c} 30, b 2.5$ ) respectively) used to assess the influence of $b$. A $20 \mathrm{~cm}$ square, two rectangles one $30 \mathrm{~cm}$ by $20 \mathrm{~cm}$ and one 30 by $10 \mathrm{~cm}$ and a $30 \mathrm{~cm}$ equilateral triangle, all of which $b=5 \mathrm{~cm}$ were used to assess shape variations (called Square $\left(L_{c} 20, b 5\right)$ ), Rectangle ( $L_{c} 30$ by 20, $b 5$ ), Rectangle ( $L_{c} 30$ by $10, b 5$ ) and Triangle ( $\left.L_{c} 30, b 5\right)$ respectively). $r$ was investigated by preparing two models with 6 mm diameter and $6 \mathrm{~mm}$ deep holes drilled into the surface. The surface density of these holes was every $5 \mathrm{~cm}$ for the model Square $\left(L_{c} 30, b 5, r 5\right)$, and every $2.5 \mathrm{~cm}$ for Square $\left(L_{c} 30, b 5, r 2.5\right)$. To investigate the variation of width with $b$, a $20 \mathrm{~cm}$ long, $2.5 \mathrm{~cm}$ thick square was moulded centrally onto the surface of a $30 \mathrm{~cm}$ long, $2.5 \mathrm{~cm}$ thick square (Underwater Ram). This was intended to simulate a floe with a larger under water width. This model was inverted to represent a floe with a reduced under water width (Overhang). To investigate the differences between an iceberg, which will have a draft often much larger than an ice floe due to its process of formation from glacial calving, a $20 \mathrm{~cm}$ sided cube was constructed (Cube $\left(L_{c} 20\right)$ ). These floe models were subjected to a range of $\lambda$ from 40 to $290 \mathrm{~cm}$ (40 to $290 \mathrm{~m}$ in the prototype) and $H$ from 1.8 to $16 \mathrm{~cm}$ (1.8 to $16 \mathrm{~m}$ in the prototype). The waves produced in the flume, therefore, varied from deep water $(d>1 / 2 \lambda)$ to intermediate water $(1 / 20 \lambda<d<1 / 2 \lambda)$. For the tests involving changing $\lambda$ but constant wave steepness, in order to avoid the floes rolling and brief losses of LED acquisition by the cameras (drop outs) due to splash and momentary submergences at large steepness while still attempting to examine severe seas, steepness was set at 0.044 . The test conditions are given in Table 2 .

Table 1. Ice floe model details. 
Before each test $d$ was confirmed $=0.9 \mathrm{~m}$, and the wave probes and cameras were checked and calibrated

if necessary. Regular waves were generated by selecting the desired $f$ and $H$. The model was then placed within the test section, at a point approximately level with the upstream cameras 6 and 7 (Figure 1). The model was orientated as close to the centreline of the flume as possible and with the desired side parallel to the incident waves. For the majority of runs this was $L_{c}$ while in some runs for the triangular and rectangular models $L_{c}$ was orientated normal to the incident waves to investigate any affect this may have. The orientation of the model could only be visually confirmed from comparison with the side wall and the motion capture user interface's live-feed and as such a small tolerance was allowed. It was found that any offset in the orientation of the model was nullified once the model reached quasi-steady state, and any that were not within this tolerance would rotate fully to present a different side to the incident waves and, therefore, that data was discarded. Care was taken to ensure that there was no residual current or significant motion in the flume by visually monitoring the real-time position of the model via the camera system before each run. To ensure that there was no spurious current forming within the flume during wave generation, a series of tests were carried out to measure the current velocity in various wave conditions covering the range of $H$ and $\lambda$ values, including the upper and lower limits given in Table 2. Using a Nortek Vectrino Acoustic Doppler Velocimeter, 1.5 minute long time series velocity measurements (generally far greater than the duration of individual runs of between 45 and 60 seconds) were obtained along the centreline and at 25, 50 and $75 \mathrm{~cm}$ locations towards the flume wall. The mean values of longitudinal velocity showed a drift of flow with the direction of wave propagation as would be expected. The values were the same at each measurement position indicating that there was no spurious current developing during wave generation.

To ensure repeatability each run of a particular test condition was repeated three times, with the average motion taken. Later, for logistical reasons this was reduced to two repeats per test to allow a wide range of models and parameters to be examined, while still ensuring accurate production of test conditions and recording of model motion.

\subsection{Data processing}

Once the data was recorded by the PhaseSpace server, the time-series data for each LED was visually 
1 quality checked using PhaseSpace RECAP2 motion tacking software. Figure 3 shows an example of the ideal data outcome which was one of a smooth time series of heave and surge motion with few spikes and dropouts. Spikes are often due to reflections of the LEDs on the water surface that are picked up by the cameras, where as drop-outs are complete momentary losses of one or more LED by the system (Figure 3). The spikiness of the data was analysed visually and with the method of Goring and Nikora, (2002). Data that did not pass this quality control i.e., contained too many spikes and / or too many LED drop outs was discarded and the test repeated. Only once a satisfactory data set was obtained, such as that in Figure 3, was the ice motion analysed.

The motion of the floe model was averaged over 5 wave periods for each run, and the average of all runs for each test condition was recorded. Only the Surge $(X)$ and Heave $(Y)$ motion and velocity are reported in here as these are the most important rigid body motions concerning structure impacts. The time series motion $X$ and $Y$ traces exhibit periodic cycles at the same frequency of the incident waves. Surge, which consists of a steady drift component and an oscillating component is computed from five cycles once a quasi-steady state has been reached (see Section 3.3). From the recorded displacement, velocity is also calculated. Heave is recorded from the average of five cycles after a quasi-steady state in the heave motion is reached and velocity is calculated from the recorded displacement. This is set at the same point defined for the surge, with steady state confirmed by computing the standard deviation of the averaged heave values. The motions of the four LEDs are resolved to the centre of gravity (CG) of the model.

Figure 3. An example of the raw time series displacement trace record ( $y$ axis scale in $\mathrm{m}$ ) of four LEDs as a function of time ( $x$ axis scale $240 \mathrm{fps}$ ). As the LEDs are positioned in parallel pairs normal to the incident wave direction (one pair at the front, towards the wave source, and the second at the rear), only two traces are seemingly observed as each pair appears to act as one LED in this example (large $\lambda$ relative to $L_{c}$ ). Individual LED traces are still recorded and can be displayed indivisually. It is also easier to observe them at a smaller scale and more so at smaller $\lambda$ relative to $L_{c}$ where the front and rear LEDs tend to

\section{Initial results and analysis}

\subsection{Validation of test}


Figure 4a-b shows the $Y$ and $X$ RAOs as a function of $\lambda / L_{c}$ for cube $\left(L_{c} 20\right)$ compared with the data of Lever et al. (1988a). Initially the wave steepness $H / \lambda=0.044$ was found to induce full rolling of the cube at most $\lambda / L_{c}$. Therefore, $H / \lambda$ was set to a lower value of 0.02 to prevent rolling and to allow comparison with Lever et al. (1988a). They tested three cubes with $L_{c}=17.5,34.6$ and $51.9 \mathrm{~cm}$ at $H / \lambda=0.016-0.025$. The heave RAO follows the trend observed by Lever et al. (1988a) closely, which was also the case for cube $\left(L_{c} 20\right)$ in $H / \lambda=$ 0.044 for the $\lambda / L_{c}$ values where rolling did not occur, the results of which are not shown here. However, the general trend of an increase to a peak surge RAO at approximately $\lambda / L_{c}=7$ followed by a decrease is different to the observation in Lever et al. (1988a). Significant sway and roll motions were observed over the range of $\lambda L_{c}$. In an attempt to repeat their results the cube was also subject to the precise $\lambda$ and $H$ used by Lever et al. (1988a). However, it appeared to follow a similar scattered distribution as seen with the previous test. The tests on the cube were repeated several times and comparing with a second cube of the same size with approximately consistent results, leading to the conclusion that the surge motion of the cube is inherently complex. Therefore, with the good agreement between Lever et al. (1988a) in the heave response of the cube, and the surge results for the floe models showing excellent consistency in general trends (see section 3.2 onwards), we are able to reduce the likelihood that this is due to a specific experimental error and regard our methodology as suitably valid.

Figure 4. The heave (a) and surge (b) RAO of cube $\left(L_{c} 20\right)$ compared with the data of Lever et al. (1988a).

\subsection{Influence of Re and $r$}

Figure 5(a-b) shows the heave and surge RAOs of the three square models square $\left(L_{c} 30, b 5\right)$, square ( $L_{c}$ 24, $b 4$ ) and square ( $L_{c}$ 20, $b$ 3.3) which represent the same floe model at different $F r$ scales, as a function of $\lambda L_{c}$. Heave shows little scatter and no discernible trend with scale factor; all three models display an increase in heave response with $\lambda / L_{c}$ to an asymptotic value approximately $0.9-1$. Surge, (Figure $5 b$ ) shows a monotonic decrease with increasing wavelength to a value of approximately $0.5-0.7$. The general indication is that scale factor does not affect the motion.

The effect of $r$ is an important consideration for the extrapolation of smooth surface models to prototype floes of highly variable surface roughness. Figure 6(a-b) shows the square $\left(L_{c} 30, b 5\right)$, square $\left(L_{c} 30, b 5, r\right.$ 
$15)$ and square $\left(L_{c} 30, b 5, r 2.5\right)$ heave and surge RAOs as a function of $\lambda / L_{c}$. There is no trend in heave with

2 respect to $r$; all show a monotonic increase to an asymptotic value of approximately 0.9 from $\lambda / L_{c}=4$.

3 Likewise, for surge $r$ shows no variability; all present a decrease to an asymptote of approximately 0.9-1 from $4 \lambda / L_{c} \geq 6$.

$5 \quad$ The implication from Figures 5 and 6 is that viscous effects and surface roughness do not appear to play a significant role in the kinematics of the floe model motion. The application of Froude criterion seems to be the most appropriate scaling criterion and allow cautious extrapolation of model floe motion observed in this study to the prototype.

Figure 5. RAOs for heave (a) and surge (b) for the square ( $\left.L_{c} 30, b 5, r 5\right)$, scale: 100:1, square $\left(L_{c} 24, b 4\right)$ scale: $125: 1$ and square $\left(L_{c} 20, b\right.$ 3.3), scale: 150:1 floe models.

Figure 6. The heave (a) and surge (b) RAOs for the smooth and roughened $L_{c}=30 \mathrm{~cm}$ squares.

\subsection{Time series motion of floe models}

Identifying the fundamental motion of a floe model in regular waves is an important first step in defining ice floe kinematics. Figure 7 represents a typical time-series trace of the displacement of the centroid between the four LEDs on the surface of square $\left(L_{c} 30, b 5\right)$. The test conditions are $\lambda=300 \mathrm{~cm}$ and $H=14.8 \mathrm{~cm}$. The surge trace (solid line) visually appears to reach a quasi-steady state between 20 and 25 seconds. Heave (dashed line) reaches equilibrium after a similar amount of time. The two traces are slightly out of phase; the trough of the heave motion occurs fractionally earlier than for the surge.

To explore this further, Figure 8(a-f) and Figure 9(a-d) show a series of stills from a video taken of Square ( $L_{c} 30, b 5$ ) at $\lambda=180 \mathrm{~cm}$ and $H=5 \mathrm{~cm}$ and $\lambda=40 \mathrm{~cm}$ and $H=5 \mathrm{~cm}$ respectively. The heave motion at large $\lambda$ follows the sinusoidal shape of the free surface as the wave passes. The surge shows a maximum (positive $x$ ) horizontal displacement from the starting position (Figure 8a) just after the passage of the wave crest in (Figure 8d). The floe then moves backwards (negative $x$ ) from this position to the new horizontal displacement at the start of the next period (Figure 8e). The flow also rolls slightly forward on the wave rise causing the leading edge to become submerged (Figure 8b) and slightly backwards on the wave fall (Figure 
8d) causing overtopping from the rear towards the centre.

At shorter $\lambda$ as shown in Figure 9(a-d) the floe interacts with two waves at once preventing it from heaving as a fluid particle, while surge is characterised by a continued forward motion, or drift, that although varies in velocity does not include a negative $x$ component. This is discussed and quantified further in Section 3.4. The basic motion of the floe models described above is as expected and analogous to glacial icebergs (e.g., Lever et al. 1988a) and most other free floating objects.

Figure 7. The time series $\mathrm{X}$ (surge: heavy black line) and Y (heave: light black line) trace for the surface centroid of square ( $\left.L_{c} 30, b 5\right)$ in regular waves of $\lambda=300 \mathrm{~cm}$ and $H=14.8 \mathrm{~cm}$.

Figure 8. (a-f) A selection of video stills taken over one wave period of square $\left(L_{c} 30, b 5\right)$ in regular waves of $\lambda=180 \mathrm{~cm}$ and

$$
H=5 \mathrm{~cm} \text {. }
$$

Figure 9. (a-d) A selection of video stills taken over one wave period of square $\left(L_{c} 30, b 5\right)$ in regular waves of $\lambda=40 \mathrm{~cm}$ and

$$
H=5 \mathrm{~cm} \text {. }
$$

\subsection{Determination of drift velocity $V_{d}$}

Figure 10(a) shows the longitudinal displacement time series trace for Square $\left(L_{c} 30, b 5\right)$ in a wave of $T=$ $0.947 \mathrm{~s}$ and $\lambda=140 \mathrm{~cm}$. The trace shows both the period-averaged surge motion (the drift), and the oscillating surge motion (Figure 10b). Both motions and their corresponding velocities are important quantities for ice motion. $V_{d}$ can be calculated via two methods (for example, Huang et al. 2011). The first calculates the periodaveraged $V_{d}$ by finding the horizontal displacement between two peaks and dividing by the $T$. In Figure 10c, quasi-steady state has been achieved after approximately $25 \mathrm{~s}$ and $V_{d}$ calculated as $\approx 6.9 \mathrm{~cm} \mathrm{~s}^{-1}$. The second method applies a line of best fit to a section of the time series after the drift appears quasi-steady. A linear regression is made of a segment of time series between 25 and $33 \mathrm{~s}$ (Figure 10d). This gives a $V_{d}=7.1 \mathrm{~cm} \mathrm{~s}^{-}$

${ }^{1}$. In this study the first approach is used with a small modification. The trough to trough (analogous to peak to peak) horizontal displacement and time difference for five motion cycles is taken and averaged. The five waves are taken after a quasi-steady state has been reached, and the standard deviation of the five drift velocities calculated from the cycles is used to confirm this. This method is in keeping with how the heave, 
heave velocity and surge are also calculated. This method gives a $V_{d}=6.82 \mathrm{~cm} \mathrm{~s}^{-1}+/-2 \mathrm{~mm} \mathrm{~s}^{-1}$. At shorter $\lambda$ it becomes harder to visually identify the 'peak' of each cycle leading to the best fit method being used to confirm the accuracy above method.

Figure 10. For square $\left(L_{c} 30, b 5\right)$ in regular waves of $T=0.947 \mathrm{~s}$ and $\lambda=140 \mathrm{~cm}$ : (a) time-series $x$ trace for surge motion; (b) segment of time series showing two cycles; (c) peak averaging method of calculating drift velocity and (d) the linear regression method.

The floe drift data collected was compared with $V_{d}$ as calculated using Stokes theory. Before the drift velocity data are discussed, however, some limitations to the validity of this comparison must be addressed. The appropriate comparison of Stokes with the data depends on confirmation of the wave conditions being linear. There are two particular nonlinear phenomena that must be quantified; nonlinearity in the waves and overtopping of the waves onto the floes (green water). To determine nonlinear behaviour in the waves, the $H$ time series record from the wave probes was deconstructed into its component frequencies by way of a Fast Fourier Transform (FFT). Small magnitude harmonic distortions in $k a$ values $\geq 0.15$ were detected indicating that the wave conditions are not strictly linear at such $k a$ values. The detected harmonic frequencies were very low in magnitude, however, and apart from the slight increase of scatter in the non-linear range of $k a$, the main trends in the data discussed below appear to remain across the whole range of the data, suggesting that the effect that the nonlinear higher harmonics have on the floe motion is not great. Visual observations of the floe motion in each wave steepness indicated that green water was only present at $k a$ values $\geq 0.16$. Therefore, the range of $k a$ where the floe response may be affected by nonlinear inputs is $k a \geq 0.15$, as shown on Figure 11a-d.

Figure 11(a) shows the drift velocities for square $\left(L_{c} 30, b 5\right)$ and square $\left(L_{c} 20, b 5\right)$ normalised with wave celerity $\left(V_{d} / c\right)$ as a function of wave steepness $k a$, where $k=$ wave number and $a=$ wave amplitude. Also shown is the $V_{d} / c$ as calculated using Stokes theory. The drift in both cases follows the quadratic relationship of the Stokes drift velocity curve as a function of $k a$ though the actual values are slightly greater. The range of $k a$ values where non-linear conditions are observed are annotated on Figure 11(a-d). Square ( $\left.L_{c} 30, b 5\right)$ presents slightly greater $V_{d}$ than the smaller square $\left(L_{c} 20, b 5\right)$. The data in the range $k a=0-0.16$ agrees quite well with Huang et al. (2011) for their $20 \mathrm{~cm}$ sided, $4.5 \mathrm{~cm}$ thick square, and the trend appears to 
continue at the larger $k a$ values tested in this study. On a side note, the similarity between these two models indicates that floe flexure appears to an extent, relatively unimportant at the $k a$ values tested; Huang et al. (2011)'s square model is $0.5 \mathrm{~cm}$ thinner than square $\left(L_{c} 20, b\right.$ 5) yet still does not show any appreciable difference due to being made of more compliant polyethylene material. Figure 11(b) shows the square $\left(L_{c} 30\right.$, $b 5$ ), square ( $\left.L_{c} 30, b 5, r 2.5\right)$ and square $\left(L_{c} 30, b 5, r 5\right)$ floe models, from which there appears to be no influence on the $V_{d}$ due to $r$. In Figure 11(c) the velocity for the rectangle ( $L_{c} 30$ by 20, $b 5, L_{c}$ normal) and triangle ( $L_{c} 30, b 5$, streamline normal) both appear to follow the Stokes curve reasonably well, which is also the case for square ( $\left.L_{c} 20, b 5\right)$, (Figure 11a). The indication is that the smaller surface area that these models present to the incident waves acts to reduce $V_{d}$. This appears to show different behaviour to the results of Wake et al. (1987), who observed no affect of the floe length parallel to the incident waves on $V_{d}$ for floes of $L_{c}>>\lambda$, suggesting that $L_{c}$ has an effect at the lower $L_{c}$ range investigated in this study. In Figure 11(d), the underwater ram and square $\left(L_{c} 30, b\right.$ 7.5) models show significantly greater $V_{d}$ than achieved by the square ( $L_{c} 30, b 2.5$ ), overhang and the Stokes curve. The shape of the curve also differs; square $\left(L_{c} 30, b 7.5\right)$ exhibits an approximately linear relationship with $k a$ while underwater ram shows a concave quadratic relationship. Interestingly, unlike underwater ram, the overhang floe follows the trend of square $\left(L_{c} 30, b 5\right)$ quite closely, indicating that the relationship between $k a$ and $L_{c}$ as a function of $b$ is quite complex. Our data is in agreement with Huang et al. (2011) yet as they show for their data, it appears to show the opposite trend to the theory given in Shen and Zhong, (2001) and Grotmaarck and Meylan, (2006). There is no need to repeat their analysis for this data, as the fact that observed $V_{d}$ for the square $\left(L_{c} 20, b 5\right)$ reflect their $20 \mathrm{~cm}$ sided $4.5 \mathrm{~cm}$ thick square, adds weight to their discussion showing that existing theory underestimates the $V_{d}$. Despite best efforts, the motion of the floes is not entirely linear; there is always some roll and sway, both of which will have an effect on $V_{d} / c$. Roll is caused by the floe being orientated slightly non-parallel to the incident waves. To quantify these modes of motion, the average roll angle and sway displacement across each of the 5 wave cycles from which the average of $V_{d} / c$ is calculated (as described above), is given in Table 3 . The values are very small suggesting that $V_{d} / c$ calculated from these runs is relatively unaffected by these modes.

Figure 11a-d. Plots of $V_{d} / c$ as a function of wave steepness for several different floe models.

Table 3. The mean roll angle in degrees and sway in meter over the range of wave steepness for the floes plotted in Figure 11. 
Figure 12(a-d) shows drift velocity as a function of $\lambda$ with the same $H / \lambda=0.044$. The general trend is the

same for all floe models; as $\lambda$ increases $V_{d}$ decreases with respect to $c$ until an asymptote is reached at approximately $\lambda>200 \mathrm{~cm}$. There are variations in values, however; square $\left(L_{c} 20, b 5\right)$ shows a $V_{d}$ that is approximately 30-50\% lower than square $\left(L_{c} 30, b\right.$ ) (Figure 12a). From Figure 12(b), there is no variation due to $r$. Lower $V_{d}$ is also observed for triangle $\left(L_{c} 30, b 5\right)$ and rectangle ( $L_{c} 30$ by 20, $b 5$ ) (both with $L_{c}$ normal and parallel to the incident wave), suggesting that the smaller floe size reduces $V_{d}$ (Figure 12c). In Figure $12(\mathrm{~d})$, the $V_{d}$ of the square $\left(L_{c} 30, b 5, r 2.5\right)$, square $\left(L_{c} 30, b 5, r 5\right)$ and square $\left(L_{c} 30, b 7.5\right)$ is similar until $\lambda>120 \mathrm{~cm}$ after which square $\left(L_{c} 30, b 2.5\right)$ shows significantly lower velocities. At $\lambda>60-120 \mathrm{~cm}$ the overhang and underwater ram models $V_{d}$ is greatly increased and decreased from square $\left(L_{c} 30, b 5\right)$ respectively. This suggests a large sensitivity of $V_{d}$ due to varying width of the model, as seen for wave steepness. The observed peak at $\lambda=60 \mathrm{~cm}$ for the square floe models, as well as rectangle ( $L_{c} 30$ by 20, $b 5$ ) ( $L_{c}$ parallel) will be discussed in the next section.

Figure 12a-d. Plots of drift velocity as a function of relative length for several different floe models.

\subsection{Oscillating surge component}

As shown in Figure 10(b), the overall surge motion also includes an oscillatory motion as well as the drift discussed above. At longer $\lambda$ this describes the maximum forward displacement, and at shorter $\lambda$ describes a period of greatest velocity achieved over one wave cycle. The maximum displacement and velocity achieved within one wave cycle is an important quantity in the calculation of instantaneous impact forces. Figure 13 shows the drift and oscillating surge components of Square $\left(L_{c} 30, b 5\right)$ as a function of $\lambda / L_{c}$. At $\lambda / L_{c}<\sim 5.3$, the drift surge represents the maximum horizontal displacement during the wave cycle. At $\lambda / L_{c}>5.3$ this is characterised by the oscillating surge. Essentially, in larger $\lambda L_{c}$, the floe moves in particle-like orbital motions. This transition occurs between $\lambda / L_{c}=4.6-6$ for all the models tested. 
In the following sections, the surge will be plotted showing the maximum displacement for each test condition within one period. Which surge component represents this is dependent on $\lambda$ and will be discussed.

3.6 The estimation of maximum velocity and acceleration

Velocity and acceleration of a floe at the point of impact are important quantities in the calculation of impact force through various methods such as the Morison equation. Figure 14 is a time series record of surge displacement, calculated velocity and acceleration for square $\left(L_{c} 30, b 5\right)$ at $T=1.389 \mathrm{~s}, \lambda=290 \mathrm{~cm}$ and $H=$ $14.81 \mathrm{~cm}$. Figure 14 shows a phase difference in accordance to simple harmonic motion between displacement, velocity and acceleration as a function of time, which is typical for all models and wave parameters tested. The instantaneous $V_{X}$ for each cycle of motion occurs at the approximate mid-point between any one trough and peak in displacement. For this floe model, $V_{X}$ appears to be $\approx 0.3 \mathrm{~m} \mathrm{~s}^{-1}$. This represents a surge velocity of $0.82 V_{p}$ (where $V_{p}=$ theoretical particle velocity). Instantaneous maximum absolute acceleration $A_{X}$ occurs when velocity is $\approx 0$, and in this case is $\approx 0.12 \mathrm{~m} \mathrm{~s}^{-2}$.

Figure 14. Time series displacement, velocity and accelerations during the quasi-steady state period of square $\left(L_{c} 30, b 5\right)$ at $\mathrm{T}$ $=1.389 \mathrm{~s}, \lambda=290 \mathrm{~cm}$ and $\mathrm{H}=14.81 \mathrm{~cm}$.

By plotting the time series displacement as in Figure 14, the maximum recorded instantaneous velocity $V_{X}$ and $Y_{V}$ and acceleration $A_{X}$ and $A_{Y}$ are determined. Figure 15 shows the calculated heave and surge velocities for cube $\left(L_{c} 20\right)$, square $\left(L_{c} 20, b 5\right)$ and square $\left(L_{c} 30, b 5\right)$ normalised with particle velocity $V_{p}$ according to linear wave theory. Note that for cube $\left(L_{c} 20\right), H / \lambda=0.02$ to prevent rolling, while for square $\left(L_{c} 20, b 5\right)$ and Square $\left(L_{c} 30, b 5\right) H / \lambda=0.044$. The trends in velocity are essentially the same as for displacement. In heave motion floes reach $0.8 V_{p}$ and greater at longer $\lambda$, with the shorter $\lambda$ inhibiting the floes velocity. The floes generally do not exceed fluid particle velocity, where as cube $\left(L_{c} 20\right)$ does significantly between $\lambda / L_{c}=5.3-$ 12. $V_{X}$ remains at approximately $0.7-0.9 V_{p}$ and increases slightly at longer $\lambda$. As the remaining floe models calculated heave and surge velocities also followed the distribution of displacement, this data is not presented 
1 The interesting implication of this data is that floe velocity does not exceed particle velocities at longer $\lambda$ to the extent as seen for cube $\left(L_{c} 20\right)$ and the glacial ice models tested in Lever et al. (1988a). The statement in ISO 19906 (ISO 2010) suggests “...Pieces of ice with maximum dimension less than 1/15 of the incident wavelength (i.e. $\lambda / L_{c} \geq 15$ ) can be conservatively assumed to follow water particle velocity...” In light of the present data, an additional, more conservative statement might suggest, that the lower $L_{c}$ limit be set to $1 / 5$ of $\lambda$ as although velocities are not greater than $V_{p}$ they appear to have reached an asymptote well within 0.8 $V_{p}$ and remain constant with increasing $\lambda$. The presence of near particle-like velocities at shorter $\lambda$ is an important consideration for the design process.

Figure 15. The heave (a) and surge (b) velocity normalised with theoretical particle velocity for square ( $\left.L_{c} 30, b 5\right)$, square $\left(L_{c}\right.$

$$
20, b 5) \text { and cube }\left(L_{c} 20\right) \text {. }
$$

As at $\lambda L_{c}>5$ the relative velocity $V_{X} / V_{P}$ and $V_{Y} / V_{P}$ has reached an asymptote (Figure 15), the maximum absolute velocity occurs at the longest wavelength $\lambda=290 \mathrm{~cm}$ as this is associated with the largest $H$ tested $(H=14.8 \mathrm{~cm})$. Velocity and acceleration is then determined from the average of five motion cycles after the floe has achieved quasi-steady state (as in Figure 14). These results are presented in Table 4 which also shows the extrapolated velocity and acceleration maximums that would occur in the prototype (according to Froude scaling laws at a 1:100 scale ratio), and the approximate maximum kinetic energies the floe may obtain. Along with square $\left(L_{c} 30, b 5\right)$, data for square $\left(L_{c} 30, b\right.$ 7.5) and underwater ram is shown as these presented the largest velocities amongst all the tested floe models. The table also includes extrapolations for shorter period waves of $\lambda=199$ and $100 \mathrm{~cm}$. The extrapolation indicates kinetic energies of $10^{6} \mathrm{KJ}$ in magnitude are possible in the field.

Table 4. The heave and surge velocities and accelerations for selected models at selected $\mathrm{T}$ and $\lambda$, along with extrapolated

$$
\text { prototype values. }
$$

\section{The Influence of Wave and Floe Characteristics on Kinematics}

In the following section, green water was observed at $\lambda \leq 160 \mathrm{~cm}$ for all models during tests where $\lambda / L_{c}$ was varied and $H / \lambda$ was constant. No attempt was made to avoid green water, however, as the model is in 
similitude with the prototype scale. The occurrence of green water was due to relatively steeper gradient in the water surface experienced by the floe in shorter $\lambda$ resulting in it being less able to move with the water surface profile. For the wave steepness tests, where $H / \lambda$ is varied and $\lambda$ is held constant, green water was observed for $H / \lambda>0.055$. Very small magnitude $2^{\text {nd }}$ harmonics were observed in the wave time series for all the wave conditions in the variable $\lambda / L_{c}$ tests.

\subsection{Effect of $\lambda$ and $H$ on model motion}

$\lambda$ and $H$ may be thought to influence model kinematics in several ways. Assuming model motion is the same as the sinusoidal motion of the free surface, the heave and surge motions would have a linear relationship with $H$ in constant $\lambda$. That is, $Y / H$ and $X / H$ are independent of $H / \lambda$. Changes in $\lambda$, however would subject the model to changes in $c$ in the deep water range, diffraction effects at shorter $\lambda$, and to opposing wave particle motions at $\lambda \approx L_{c}$.

Figure 16 shows heave and surge RAOs for square $\left(L_{c} 20, b 5\right)$ and square $\left(L_{c} 30, b 5\right)$ as a function of $\lambda / L_{c}$ and $H / \lambda$. In Figure 16(a), diffraction of the incident waves by both models occurs for $\lambda / L_{c}<5$, and this region is characterised by suppressed heave responses. At $\lambda \rightarrow L_{c}$, the floes presumably experience opposing vertical particle motions further dampening the heave response. The heave response as a function of $\lambda / L_{c}$ shows a rapid increase to an asymptotic value of approximately $0.9 H$ from $\lambda L_{c} \geq 3.3$ and $\lambda / L_{c} \geq 5$ for square $\left(L_{c} 30\right.$, $b 5$ ) and square $\left(L_{c} 20, b 5\right)$ respectively. This is similar to the field results of Frankenstein et al (2001), though their lack of direct $H$ measurements means that it is difficult to compare results with respect to $H$. Clearly here, the RAO at the $\lambda$ tested does not exceed 1 as observed by Frankenstein et al (2001), and for icebergs by Lever et al (1998a). The trend is a quadratic function. While the trend is the same for both models, it appears $L_{c}$ has an influence on when the asymptote will be attained. On closer inspection, however, the asymptote is reached at the same $\lambda=100 \mathrm{~cm}$ for both models, indicating the value and $\lambda$ where asymptote is achieved is independent of $L_{c}$, which only affects the magnitude of the response before asymptote is reached (Figure 17a).

Figure 16(b) shows the heave response as a function of wave steepness $H / \lambda$. The value for square $\left(L_{c} 20\right.$, $b 5$ ) is generally constant at approximately $0.9-0.95 H$. $Y / H$ is $<1$ likely due to viscous dampening of the heave motion during the wave cycle. The trend appears to increase to a maximum at $H / \lambda \approx 0.05$ before 
decreasing once more. The same is observed for square $\left(L_{c} 30, b 5\right)$ though the maximum is achieved at $H / \lambda$ $=0.025$ and the following decrease with increasing steepness is essentially linear and rapid. This may be due to increased boundary layer shear and/or nonlinearity in the incident waves at higher wave steepness ratios. Indeed, more overtopping was observed at higher $H$ indicating that the model was experiencing momentary partial submergence at the peak and trough of the wave which may also account for the lower $Y / H$ observed than at lower steepness values.

Surge (Figure 16c), is greatest at $\lambda / L_{c}=2$ and 3 for square $\left(L_{c} 30, b 5\right)$ and square $\left(L_{c} 20, b 5\right)$ respectively before decreasing linearly with increasing $\lambda$. Both floes reach a minimum RAO at a $\lambda=200$ before gradually increasing and exceeding unity. At $\lambda>180 \mathrm{~cm}$, the waves are in intermediate water depth, and therefore, they will follow elliptical orbits meaning the surge RAO ought to gradually increase beyond 1 with increasing $\lambda$ (Masson and LeBlond, 1989). When plotted as a function of $\lambda$ alone, the point and value of the surge asymptote $\left(\lambda / L_{c} \approx 5\right.$ to 6 , and $X / H \approx 1$ respectively), like for heave, is apparently not influenced by $L_{c}$ (Figure17b). This region of $\lambda / L_{c}=5$ to 6 also differentiates the surge motion characterised by the oscillating surge component $\left(\lambda / L_{c}>6\right)$ and the period-averaged drift $\left(\lambda / L_{c}<5\right)$. The data implies that shorter $\lambda$ tend to produce greater relative surge motions, though the absolute surge motions at smaller $\lambda$ are relatively small compared to those at higher $\lambda$ for both models. The location of the peak surge is at $\lambda=2 L_{c}=0.6 \mathrm{~m}$ for both models, is also observed for various other models (as discussed later). Possible explanations include: 1), inherent non-linearity in the wave generation process at $\lambda / L_{c} \leq 2$; very short $\lambda$ may be more susceptible to friction and viscous losses in the flume, and 2), the effect of opposing directional forces from separate waves being applied along the floe's length at $\lambda / L_{c} \leq 2$. However, neither suggestion adequately explains the behaviour of square $\left(L_{c} 20, b 5\right)$ which reaches a peak at $\lambda / L_{c}=3$. The cause, therefore, remains unclear from the current data.

The surge response shows a linear and approximately monotonic increase with $H$ (Figure 16d), though there is some scatter for square $\left(L_{c} 30, b 5\right)$, particularly at lower $H / \lambda$. At this $\lambda(=180 \mathrm{~cm})$ the surge is characterised by the oscillating component. The surge, however, does not appear to be proportional to wave energy $E=1 / 8\left(\rho g H^{2}\right)$ as the response would be a quadrupling of surge for a doubling of $H$. For both models surge exceeds 1 at $H / \lambda \approx 0.06$. Presumably, the trend may continue to increase with increasing $H$ at least until $H / \lambda \geq 0.17$, after which waves will break and the relationship may change. 
Figure 16. The heave (a, b) and surge (c, d) RAO of square $\left(L_{c} 30, b 5\right)$ and square $\left(L_{c} 20, b 5\right)$ as a function of relative length (a, c) and wave steepness (b, d).

Figure 17. Heave (a) and Surge (b) RAO as a function of $\lambda$.

4.2 Influence of $b$

Figure 18(a) shows the $Y / H$ RAO of square $\left(L_{c} 30, b 5\right)$, square $\left(L_{c} 20, b 5\right)$ and the cube as a function of $\lambda / L_{c}$. This demonstrates a fundamental difference in the heave response of the low $b$ ice floe and a large $b$ glacial iceberg. The larger draft of the larger mass cube $\left(L_{c} 20\right)$ renders it sensitive to resonances in heave motion, manifest where $Y$ exceeds unity at approximately $\lambda / L_{c}>6$. Square $\left(L_{c} 20, b 5\right)$ is insensitive to the same resonances and never exceeds a heave response of unity. The reason for this appears to be $b$ and not floe mass (as the larger mass square $\left(L_{c} 30, b 5\right)$ heave response is the same as square $\left.\left(L_{c} 20, b 5\right)\right)$. The flattened shape and lower $b$ of square $\left(L_{c} 20, b 5\right)$ may result in it being subject to smaller inertial restoring forces than cube $\left(L_{c} 20\right)$; it appears to act as a 'cap' on top of the wave thereby limiting its response. That is, the floe experiences heave inputs at $\lambda>L_{c}$ that, due to its relatively large surface area, vary in magnitude across the surface of the floe, something which cube $\left(L_{c} 20\right)$ 's larger $b$ appears to be unaffected by. At $\lambda \rightarrow$ $L_{c}$, the floe would presumably experience opposing vertical particle motions that would further dampen the heave response. If this was truly an issue of floe mass, however, the larger mass square $\left(L_{c} 30, b 5\right)$ would be expected to present resonances; this is, however, not the case. Its responses are the same as square $\left(L_{c} 20, b\right.$ 5), implying the increased $b$ is the most important influence on the motion. Furthermore, the floe would experience a greater portion of added mass as a result of overtopping; of which the floe is much more susceptible too due to its smaller freeboard in the same wave conditions as cube $\left(L_{c} 20\right)$.

$b$ is investigated further in Figure 18(b) where heave responses of the three $L_{c}=30 \mathrm{~cm}$ square $\left(L_{c} 30, b 5\right)$ $\left(b / L_{c}=0.16\right)$, square $\left(L_{c} 30, b 7.5\right)\left(b / L_{c}=0.25\right)$ and square $\left(L_{c} 30, b 2.5\right)\left(b / L_{c}=0.083\right)$ are shown. Both square $\left(L_{c} 30, b 5\right)$ and square $\left(L_{c} 30, b 2.5\right)$ show similar monotonic increase with $\lambda / L_{c}$ to an asymptote of approximately 0.9 by $\lambda / L_{c}=4$ and 6 respectively. The reduced $b$ appears to result in a decrease in heave response at lower $\lambda$. Square $\left(L_{c} 30, b 7.5\right)$, however, shows a clear sensitivity to resonance in approximately the same range of $\lambda / L_{c}$ as seen for cube $\left(L_{c} 20\right)$. The data suggests that an increase of $b$ increases the heave 
motion and a resonance-limiting $b / L_{c}$ for square, straight sided floe models of $b / L_{c}<0.25$ is implied, though this ought to be treated with caution due to the limited range of $b / L_{c}$ tested. The increase in heave response with increase in $b$ is also observed in the theoretical study of circular floes in the MIZ by Masson and LeBlond, (1989).

Figure 18. The heave RAO of square $\left(L_{c} 30, b 5\right)$, cube $\left(L_{c} 20\right)$, square $\left(L_{c} 20, b 5\right)$, (a) and square $\left(L_{c} 30, b 7.5\right)$, square $\left(L_{c}\right.$ 30, $b$ 2.5), (b).

Figure 19 shows the surge RAOs for the same models as presented in Figure 18(a-b). Figure 19(a) shows significant scatter in the surge response of cube $\left(L_{c} 20\right)$ as discussed in section 3.1. From figure 19(b), the larger $b$ of square $\left(L_{c} 30, b 7.5\right)$ increases its surge response between $\lambda / L_{c}=2.6$ to 5.3 with respect to the thinner floe models. All three models reach a similar asymptote from $\lambda / L_{c} \approx 6$ of approximately 1 . Again the transition between the oscillating surge $\left(\lambda / L_{c}>6\right)$ and the period-averaged drift surge $\left(\lambda / L_{c}>6\right)$ is observed. The presented data, in comparison with the theoretical study of Masson and LeBlond, (1989), interestingly does not show the same trend with thickness. They observed for their circular floes in the MIZ that for smaller values of $b$ giving greater RAO for surge.

Figure 19. The surge RAO of square $\left(L_{c} 30, b 5\right)$, cube $\left(L_{c} 20\right)$, square $\left(L_{c} 20, b 5\right)$, (a) and square $\left(L_{c} 30, b 7.5\right)$, square $\left(L_{c} 30\right.$, b 2.5), (b).

An ice floe whose $b$ varies across its width (i.e., its sides are not vertically straight) will experience significantly more changes to their wetted surface area during the passage of a wave than a floe of uniform width. Figure 20(a-b) shows the heave and surge RAOs of the overhang and underwater ram models which are intended to simulate floes with an overhang and an underwater ram respectively. $L_{c}$ is set as $30 \mathrm{~cm}$ for each model as this remains the longest length. Also shown are the RAOs of square $\left(L_{c} 30, b 5\right)$ and square $\left(L_{c} 30, b 2.5\right)$ for comparison.

The heave RAO for the overhang and underwater ram floe models both show greater similarity with the square ( $\left.L_{c} 30, b 2.5\right)$, than they do with square $\left(L_{c} 30, b 5\right)$; a delayed rise to asymptote and a suppression in the resonance sensitive region between $\lambda L_{c}=3.3-8$. The heave response of the underwater ram is the most 
suppressed at $\lambda / L_{c}<8$ while the overhang follows square $\left(L_{c} 30, b 2.5\right)$ quite closely. For the underwater ram, the floe model sits in the water with the surface of the lower half covered completely indicating that added mass of the water on top of this area may be suppressing the heave response. Indeed, during the heave motion the amount of overtopping of the upper half was observed to be significantly greater than with the other models. In the case of the overhang floe, the fact that its heave response is similar to square $\left(L_{c} 30, b 2.5\right)$ rather than to square $\left(L_{c} 30, b 5\right)$ suggests that the upper $30 \mathrm{~cm}$ by $2.5 \mathrm{~cm}$ thick half of the model dominates the motion. All models have reached the same asymptote by $\lambda / L_{c} \approx 8$.

For the surge response (Figure 20b), the overhang floe follows the approximate trend of square $\left(L_{c} 30, b\right.$ 5) and square ( $\left.L_{c} 30, b 2.5\right)$ closely. The underwater ram shows a different trend, reducing initially with increasing $\lambda / L_{c}$ to an asymptotic value of approximately 1.4 at $\lambda / L_{c} \geq 4$. This is a significant increase in the surge at longer $\lambda$ in comparison to the other models. The transition between the period-averaged drift and oscillation surge components occurs at $\lambda / L_{c} \approx 4$ for the underwater ram, notably sooner than for the other floes (whose transition occurs within $\lambda / L_{c} \approx 5.3$ to 6 ). A possible explanation is that due to the more frequent submersion of the underwater ram it is less affected by friction losses at the free surface in comparison to the other models, therefore achieving a greater surge and higher velocity (see section 3.6).

Figure 20. The heave (a) and Surge (b) RAO of square ( $\left.L_{c} 30, b 5\right)$, square ( $\left.L_{c} 30, b 2.5\right)$, overhang and underwater ram respectively.

\subsection{Influence of model shape}

Prototype ice floes are randomly shaped; to investigate the influence of shape on motion response, a series of shape variations were also tested in variable $\lambda / L_{c}$. Figure 21(a) shows the heave RAO for square $\left(L_{c} 30, b\right.$ 5), rectangle ( $L_{c} 30$ by 20, $b 5$ ) and rectangle ( $L_{c} 30$ by 10, $b 5$ ). The rectangular floe models were tested with $L_{c}$ parallel and normal to the incident wave direction, though there is no data for rectangle ( $L_{c} 30$ by $\left.10, b 5\right)$ $L_{c}$ normal as it rolled fully in this alignment, preventing motion capture. The heave response observed for the rectangle ( $L_{c} 30$ by 20, $b 5$ ) ( $L_{c}$ normal) is similar to square $\left(L_{c} 30, b 5\right)$. However, when $L_{c}$ was parallel to the incident wave the heave response is markedly dampened, and while the heave response increases with increasing $\lambda$, it is not as clear whether the asymptote has been achieved within the range of $\lambda$ tested. The same 
is seen for rectangle ( $L_{c} 30$ by $10, b 5$ ) with $L_{c}$ parallel, indicating that heave motion is sensitive to incident wave alignment. The differences are mainly confined to $\lambda / L_{c}<8$, beyond which the variation is much lower. The surge RAO for the same models is shown in Figure 21(b). The transition between surge components is at $\lambda / L_{c}=4.6$ for rectangle ( $L_{c} 30$ by 20,b 5 ) and 4 for rectangle ( $L_{c} 30$ by 10, $\left.b 5\right)$. Rectangle ( $L_{c} 30$ by 20 , $b 5$ ) with $L_{c}$ parallel follows the trend in surge displayed by the square $\left(L_{c} 30, b 5\right)$ model; descending with increasing $\lambda$ until $\lambda / L_{c} \approx 5$ to 6 before increasing to $\approx 1$. Both rectangle ( $L_{c} 30$ by 20, $b 5$ ) with $L_{c}$ normal and rectangle ( $L_{c} 30$ by $10, b 5$ ) with $L_{c}$ parallel display suppressed responses at $\lambda / L_{c}<6$. One factor may be the choice of $L_{c}$; if this is regarded as the length parallel to the wave then the rectangle ( $L_{c} 30$ by $\left.10, b 5\right)$ behaves similarly to square $\left(L_{c} 30, b 5\right)$ and square $\left(L_{c} 20, b 5\right)$ (that is, if rectangle $\left(L_{c} 30\right.$ by $\left.20, b 5\right)$ is aligned with the $30 \mathrm{~cm}$ side normal to the incident waves $L_{c}$ is changed from $30 \mathrm{~cm}$ to the parallel length $20 \mathrm{~cm}$, Figure 22). This implies that it is the surge motion is not very sensitive to the width of the floe with respect to the incident wave.

\footnotetext{
Figure 21. Heave (a) and Surge (b) RAO as a function of relative length for square $\left(L_{c} 30, b 5\right)$, rectangle $\left(L_{c} 30\right.$ by $\left.20, b 5\right)$ and rectangle ( $L_{c} 30$ by $10, b$ ) floe models.
}

Figure 22. Heave and Surge RAO as a function of relative length for square $\left(L_{c} 30, b 5\right)$, rectangle ( $L_{c} 30$ by $\left.20, b 5\right)$ and rectangle ( $L_{c} 30$ by $10, b$ ) floe models.

To investigate shape further, the heave and surge RAOs for the triangular model (triangle $\left.\left(L_{c} 30, b 5\right)\right)$ is shown in Figure 23. The heave and surge RAOs show no discernible variation due to direction of incident waves. Triangle $\left(L_{c} 30, b 5\right)$ appears to be sensitive to heave resonances at a similar range of $\lambda / L_{c}=3.3$ to 8 as seen for the cubic and $7.5 \mathrm{~cm}$ draft models (Figure 18a-b). This is an interesting observation as it suggests that thickness is not the only influence on the suppression of heave resonance responses. The surface area of the triangle is approximately $390 \mathrm{~cm}^{2}$ which is similar to square $\left(L_{c} 20, b 5\right)$ whose surface area is $400 \mathrm{~cm}^{2}$ and yet does not display heave resonances. Clearly certain shapes are more susceptible to heave resonance excitation than others, perhaps due to nonlinearity in the heave restoring forces experienced by these nonsquare floes over their surface area. Surge appears suppressed at lower $\lambda$ for triangle $\left(L_{c} 30, b 5\right)$ but decreases to a similar asymptotic value with increasing wavelength. For all models (except rectangle ( $L_{c} 30$ by $10, b$ 
1 5)) the largest of the two surge components was the period-averaged drift at $\lambda / L_{c}<6$ and the oscillating surge at $\lambda / L_{c}>6$. Meylan, (2002) suggests that the motion of floes much smaller than the incident $\lambda$ should not depend on strongly on shape variations, mainly due to the fact that they will not flex. The data presented above does indicate that individual floe shape does still play a significant role in response for small floes in large $\lambda$.

Figure 23. The heave (a) and surge (b) RAO of square $\left(L_{c} 30, b 5\right)$, triangle $\left(L_{c} 30, b 5\right)$ (streamline normal) and triangle $\left(L_{c}\right.$ 30, $b$ 5), $L_{c}$ Parallel.

\section{Conclusion}

This study differentiates itself from previous studies of floe kinematics in the MIZ by concentrating on small, isolated floes of varying thicknesses and shape. The floes were subject to regular waves of varying $H$ and $\lambda$ in order to elucidate the kinematic response and identify floe and wave parametric relationships that dictate the response in severe sea conditions. Specifically this included; the heave and surge motion and the influence of floe and wave variables on those motions; the existence and conditions of particle-like motion; the drift velocity, maximum velocity and accelerations achieved for particular floe and wave variables.

To achieve this, a series of scale model tests were carried out. Firstly, a validation of the Froude scaling criteria used was performed using three square shaped models of different sizes. No dependence on scale factor in heave and surge motions were observed. Tests of floe surface roughness showed no clear dependence on motion either. Therefore the scaled flume data may with caution be extrapolated to the equivalent prototype using Froude scaling criteria.

$V_{d}$ was found to increase from rest to a quasi-steady state relatively quickly with wave steepness in an approximate quadratic fashion similar to Stokes drift. $V_{d}$ is greater than the theoretical Stokes drift for the larger models, with the smaller models drift predicted reasonably well by Stokes. These observations are at odds with current theoretical predictions that suggest drift is lower than Stokes. $V_{d}$ appeared marginally sensitive to variations in model length, implying sensitivity to model surface area. The most variability was observed in thickness and width-variable thickness, and the relationship between wave steepness and floe length as a function of $b$ is quite complex. As a function of $\lambda, V_{d}$ was found to decrease to an asymptote by 
approximately $\lambda \approx 200 \mathrm{~cm}$ regardless of $L_{c}$. While the value of the asymptote was sensitive to model shape, $L_{c}$, and $b$, roughness appeared to have no observable affect.

Flow velocity trends matched the heave and surge displacements in all model cases (though only square ( $L_{c} 30 b 5$ ), square ( $\left.L_{c} 20 b 5\right)$ and Cube $\left(L_{c} 20\right)$ were presented). Heave velocities were $\geq 0.8 V_{p}$ at $\lambda / L_{c}>5$ while surge was 0.7 to $0.9 V_{p}$ at $\lambda / L_{c}>5$ and increased marginally at longer $\lambda$.

The heave and surge motions of the standard $5 \mathrm{~cm}$ thick square models were similar as a function of $\lambda / L_{c}$; shorter $\lambda$ corresponded to lower heave responses for and larger surge responses while larger $\lambda$ the heave and surge increased and reduced respectively to asymptotic values of approximately $0.9 H$. Asymptote was reached at $\lambda \approx 100$ and appeared independent of $L_{c}$. This, however, is based on a limited sample of two models, and would require further investigation to confirm.

Heave as a function of $H / \lambda$ was less clear; the expected response of a linear increase in heave as a function of $H$ was not observed. Instead there appeared to be some variation, especially a lower response at larger $H / \lambda$ which was attributed to non-linearity in the incident waves, and/or viscous forces. Surge, however, increases linearly with increasing $H / \lambda$, becoming $>1$ at approximately $\lambda / L_{c} \approx 0.06$.

Variations in floe $b$ were found to have a dramatic affect on surge and in particular heave. For straightsided square floes, relative thickness, $b / L_{c}<0.25$ were found to behave differently to $b / L_{c}>0.25$ in that there was an absence of heave resonances for the thinner floes, while the thicker floes showed significant resonances leading to $Y / H>>1$ in the region of $\lambda / L_{c}=3.3$ to 8 as seen for the cubic model. Floes with widths that varied with $b$ showed in some cases a large scatter in both heave and surge resonances. This is likely due to the nonlinear restoring forces experienced by these floe models during the heave and surge motion cycles.

Variations in floe shape appear to influence the model motion mostly at $\lambda / L_{c}<8$, after which all models tended to the same asymptote, $(\approx 0.9 H$ for heave and $\approx 1 H$ for surge). In comparison to the cubic model, the heave response was greatly suppressed for all floes. There was some sensitivity in response with alignment with respect to the incident waves, but the greatest variation was observed for floes that are not straight sided, namely the triangle, and floes with varying widths, particularly the underwater ram. These floes showed heave resonance responses, likely due to nonlinearity in the heave restoring forces along their more irregular wetted surfaces.

Comparisons of these results with the reasonably well understood case of isolated iceberg kinematics show 


\section{Acknowledgements}

The authors gratefully acknowledge the financial support provided by the Maritime and Port Authority of

5

6

7

8

9

\section{References}

[1] Arctic Climate Impact Assessment (ACIA), (2004). “Impacts of a Warming Arctic.” Cambridge University Press.

[2] Arunachalam, V. M., Murrray, J. J., and Muggeridge, D. B. (1987), 'Short Term Motion Analysis of Icebergs in Linear Waves.' Cold Reg. Sci. Technol., 13, 247 - 258.

[3] Cole, D. M. (1998), 'Modelling the Cyclic Loading Response of Sea Ice.’ Int. J. Solids Structures. 35 (31-32). 4067-4075.

[4] DNV. “Shipping across the Arctic Ocean - A feasible option in 2030-2050 as a result of global warming?” Position Paper 04-2010; 2010.

[5] Frankenstein, S., Loset, S., and Shen, H. H. (2001). “Wave-Ice Interactions in the Barents Sea Marginal Ice Zone.” J. Cold Reg. Eng., 15, 2, 91-102.

[6] Frankenstein, S., Shen, H. H. (1997). “Laboratory Observations of Ice-Floe Processes made During Long-Term Drift and Collision Experiments.” Antarct. J. US, 32 (4), 237-239.

[7] Frederking, R., Timco, G.W., (2000). “Sea Ice Floe Impacts_Large-Scale Basin Experiments.” Proc. ISOPE '00, 1, 656662. Seattle, Wash., USA.

[8] Goring, D. G., and Nikora, V. I. (2002). “Despiking Acoustic Doppler Velocimeter Data.” J. Hydraul. Eng., 128, 117126.

[9] Grotmaarck, R., Meylan, M. H. (2006). "Wave Forcing of Small Floating Bodies.” J. Waterw. Port Coast. Ocean Eng. 132, (3), 192-198.

[10] Harms, W., (1987). “Steady Wave-Drift of Modeled Ice Floes.” J. Waterw. Port Coast. Ocean Eng., 113, (6), 606-622.

[11] Huang, G., Wing-Keung, A. L., and Huang, Z. (2011). “Wave-induced Drift of Small Floating Objects in Regular Waves.” Ocean Eng., 38, 712- 718.

[12] Hughes, S. A., (1993). "Physical Models and Laboratory Techniques in Coastal Engineering.” Singapore, River Edge, NJ.

[13] Isaacson, M. and McTaggart, K. A. (1990). “Modelling of Iceberg Drift Motions near a Large Offshore Structure.” Cold Reg. Sci. Technol. 19, 47-58.

[14] ISO 19906 (2010). "Petroleum and Natural Gas Industries - Arctic Offshore Structures.”

[15] Kristensen, M., Squire, V. A., Moore, S. C. (1982). “Tabular Icebergs in Ocean Waves.” Nature, 297, 669-671. 
[16] Kwok, R., and Rothrock, D. A. (2009). "Decline in Arctic Sea Ice Thickness From Submarine and ICES at Records: 1958-2008.” Geophys. Res. Lett., 36, L15501.

[17] Lever, J. H., Diemand, D. (1985). “Measurements of Instantaneous Motions of Ice Masses at Sea: 1984 Pilot Program.” Proceedings of the $8^{\text {th }}$ International Conference on Port and Ocean Engineering Under Arctic Conditions. 2, Narsaaraauaq, Greenland.

[18] Lever, J. H., Attwood, D., and Sen, D. (1988a). “Factors Affecting the Prediction of Wave-Induced Iceberg Motion.” Cold Reg. Sci. Technol., 15, 177-190.

[19] Lever, J. H., Reimer, E., and Diemand, D. (1988b). “A Model Study of the Wave-Induced Motion of Small Icebergs and Bergy Bits.” J. Offshore Mech. Arct. Eng., 110, 101-107.

[20] Lever, J. H., Sen, D., Attwood, D. (1990). “The Influence of Shape on Iceberg Wave-Induced Velocity Statistics.” J. Offshore Mech. Arct. Eng., 112, 263 - 296.

[21] Lever, J. H., Klein, K., Mitchell, D., and Diemand, D. (1991). “Wave-induced Iceberg Motion.” Cold Reg. Sci. Technol., 20, 11-23.

[22] Masson, D. and LeBlond, P. H. (1989). "Spectral Evolution of wind-generated surface gravity waves in a dispersed ice field.” J. Fluid Mech. 202 43-81.

[23] Meylan, M. H. (2002). “Wave response of an ice floe of arbitrary geometry.” J. Geophys. Res. 107 (C1), 3005.

[24] Meylan, M.H., Squire, V.A., (1994). “The response of ice floes to ocean waves.” J. Geophys. Res. 99 (C1), $899-900$.

[25] Meylan, M.H., Squire, V.A., (1996). “Response of a circular ice floe to ocean waves.” J. Geophys. Res. 101 (C4), 8869 8884.

[26] Montiel, F., Bennetts, L. G., Squire, V. A., Bonnefoy, F. and Ferrant, P. (2013a). “Hydroelastic response of floating elastic discs to regular waves. Part 1. Wave basin experiments.” J. Fluid Mech. 723, 604-628.

[27] Montiel, F., Bennetts, L. G., Squire, V. A., Bonnefoy, F. and Ferrant, P. (2013b). "Hydroelastic response of floating elastic discs to regular waves. Part 2. Modal Analysis.” J. Fluid Mech. 723, 629-652.

[28] Murray, J. J., Guy, G. B., and Muggeridge, D. B. (1983), "Response of Modelled Ice Masses to Regular Waves and Regular Wave Groups.” Proceedings of the International Conference on Oceans, 2, San Fransisco, 1048 - 1052.

[29] Palmer, A. (2011). “Moving on from ISO 19906: what ought to follow?” Proceedings of the $21^{\text {st }}$ International conference on Port and Ocean Engineering under Arctic Conditions. Montreal, Canada.

[30] Sakai, S. and Hanai, K. (2002). “Empirical formula of dispersion relation of waves in sea ice.” Ice in the Environment: Proc 16th IAHR International Symposium on Ice. Dunedin, New Zealand. 2nd-6th Dec.

[31] Shen, H. H. Zhong, Y. (2001). “Theoretical study of drift of small rigid floating objects in wave fields.” J. Waterw. Port Coast. Ocean Eng. 127 (6), 343-351.

[32] Shirasawa, K., Eicken, H., Tateyama, K., Takatsuka, T., Kawamura, T. (2009). "Sea-ice-thickness variability in the Chukchi Sea, spring and summer 2002-2004.” Deep-Sea Res. II, 56, pp 1182-1200.

[33] Squire, V. A. (2007), “Of ocean waves and sea-ice revisited.” Cold Reg. Sci. Technol., 49 110-133. 
[34] Squire, V. A. (2011). “Past, present and impendent hydroelastic challenges in the polar and sub-polar seas.” Phil. Trans. R. Soc. A 369, 2813-2831.

[35] Squire, V.A., Dugan, J.P., Wadhams, P., Rottier, P.J. and Liu, A.K. (1995), “Of Ocean Waves and Sea-ice.” Ann. Rev. of Fluid Mech. 27 115-168.

[36] Timco, G. W., (2011). “Isolated Floe Impacts.” Cold Reg. Sci. Technol., 68 35-48.

[37] Timco, G. W., Federking, R. M. W., (1996). “A Review of Sea Ice Density.” Cold Reg. Sci. Technol., 24, pp 1-6.

[38] Toyota, T. Hass, C. and Tamura, T. (2011). "Size distribution and shape properties of relatively small sea-ice floes in the Antarctic marginal ice zone in late winter.” Deep-Sea Research II, 58 1182-1193.

[39] Turner, J., and Marshall, G. J. (2011). “Climate Change in the Polar Regions.” Cambridge University Press, Cambridge, U.K.

[40] U.S. Geological Survey (USGS). (2008). “Circum-Arctic Resource Appraisal: Estimates of Undiscovered Oil and Gas North of the Arctic Circle.” U.S. Geological Survey Fact Sheet 2008-3049.

[41] Wadhams, P., Kristensen, M., Orheim, O. (1983). “The Response of Antarctic Icebergs to Ocean Waves.” J. Geohys. Res., C, 88, 6053-6065.

[42] Wake, A., Poon. Y. -K., and Crissman, R. (1987). “Ice Transport by Wind, Wave, and Currents.” J. Cold Reg. Eng., 1, 89-103.

[43] Wang, C.D., Meylan, M.H. (2004). “A Higher-Order-Coupled Boundary Element and Finite Element Method for the Wave Forcing of a Floating Elastic Plate.” J. Fluid Stru. 19 557-572.

[44] Wehausen, J. V. (1971). “The motion of floating bodies.” Ann. Rev. Fluid Mech. 3, 231

[45] Williams, T.D., Squire, V.A. (2006). "Scattering of Flexural-Gravity Waves at the Boundaries Between Three Floating Sheets with Applications.” J. Fluid Mech. 569, 113-140.

[46] Xie, H., Acklet, S. F., Yi, D., Zwally, H. J., Wagner, P., Weissling, B., Lewis, M., and Ye, K. (2011). “Sea-ice thickness distribution of the Bellingshausen Sea from surface measurements and ICESat altimetry.” Deep-Sea Res. II. 58, pp 10391051. 


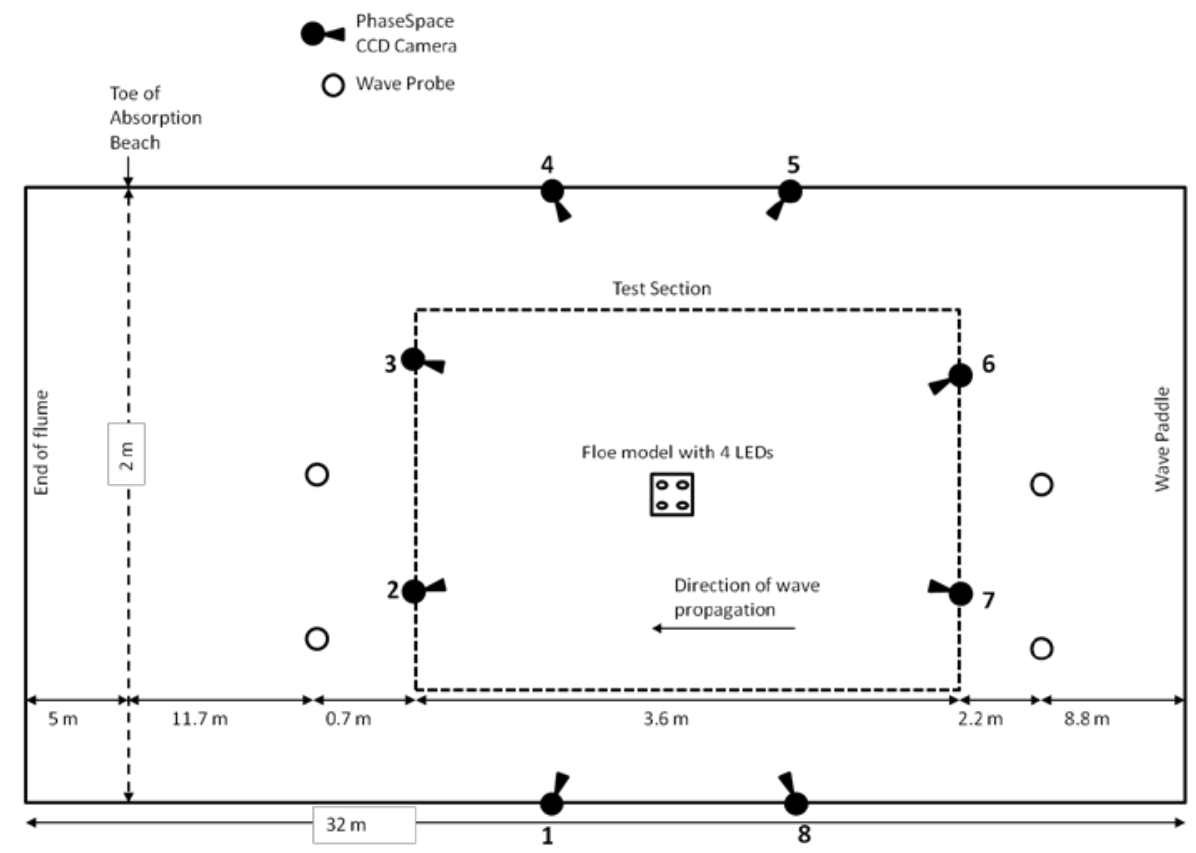

Figure 1. Schematic diagram of the experimental setup.

(a)

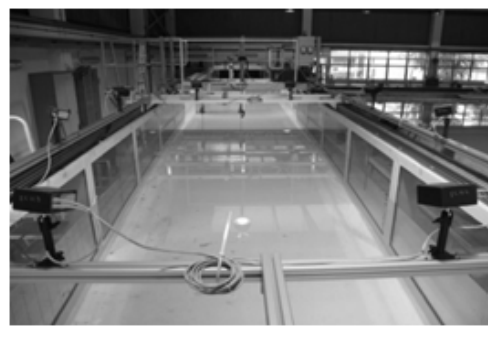

(c)

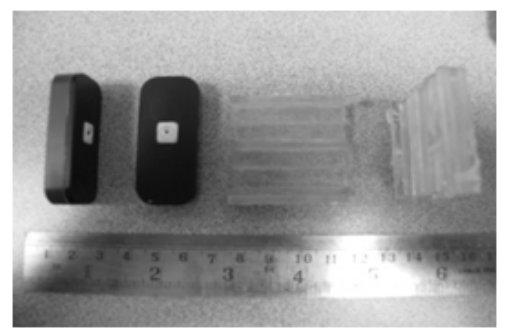

(b)

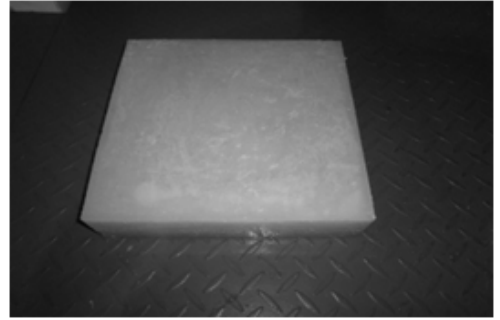

(d)

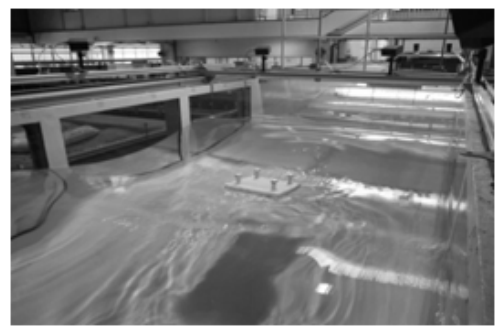

Figure 2. (a) Image of the PhaseSpace camera set-up; (b) image of a floe model; (c) two Stylus LED units and stands and (d) the model with the LEDs units during a test. 


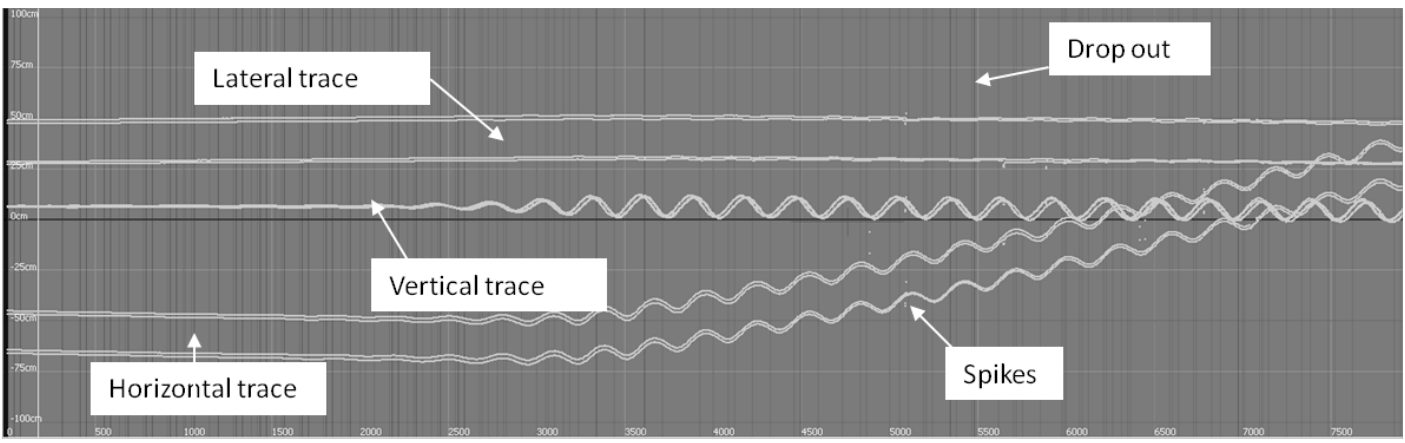

Figure 3. An example of the raw time series displacement trace record ( $y$ axis scale in $\mathrm{m}$ ) of four LEDs as a function of time ( $x$ axis scale $240 \mathrm{fps}$ ). As the LEDs are positioned in parallel pairs normal to the incident wave direction (one pair at the front, towards the wave source, and the second at the rear), only two traces are seemingly observed as each pair appears to act as one LED in this example (large $\lambda$ relative to $L_{c}$ ). Individual LED traces are still recorded and can be displayed indivisually. It is also easier to observe them at a smaller scale and more so at smaller $\lambda$ relative to $L_{c}$ where the front and rear LEDs tend to move out of phase.

(a)

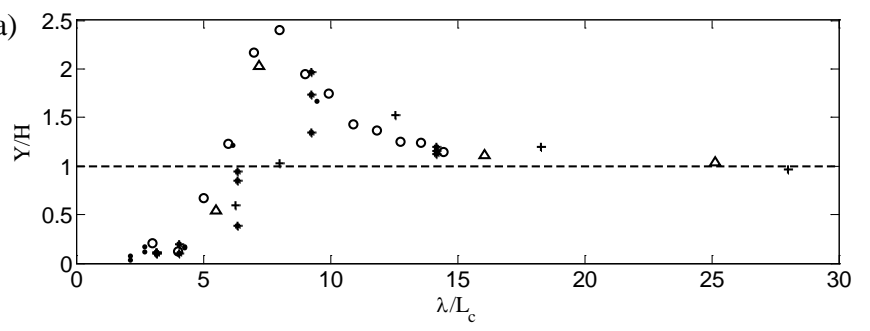

(b)

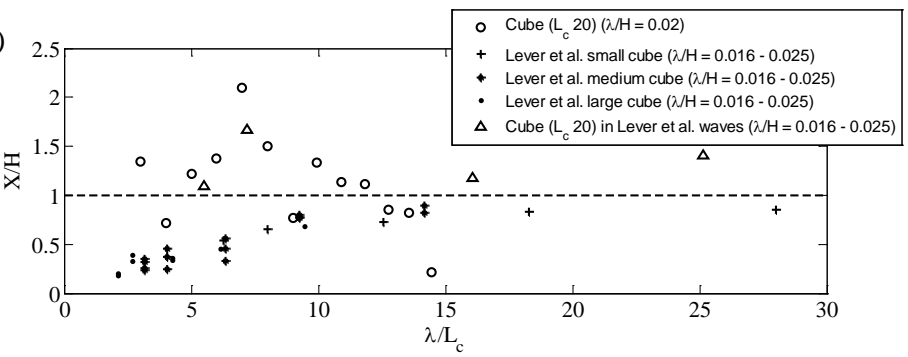

Figure 4. The heave (a) and surge (b) RAO of cube ( $\left.L_{c} 20\right)$ compared with the data of Lever et al. (1988a). 



Figure 5. RAOs for heave (a) and surge (b) for the square $\left(L_{c} 30, b 5, r\right.$ 5), scale: 100:1, square $\left(L_{\mathrm{c}} 24, b 4\right)$ scale: $125: 1$ and square $\left(L_{c} 20, b 3.3\right)$, scale: $150: 1$ floe models.
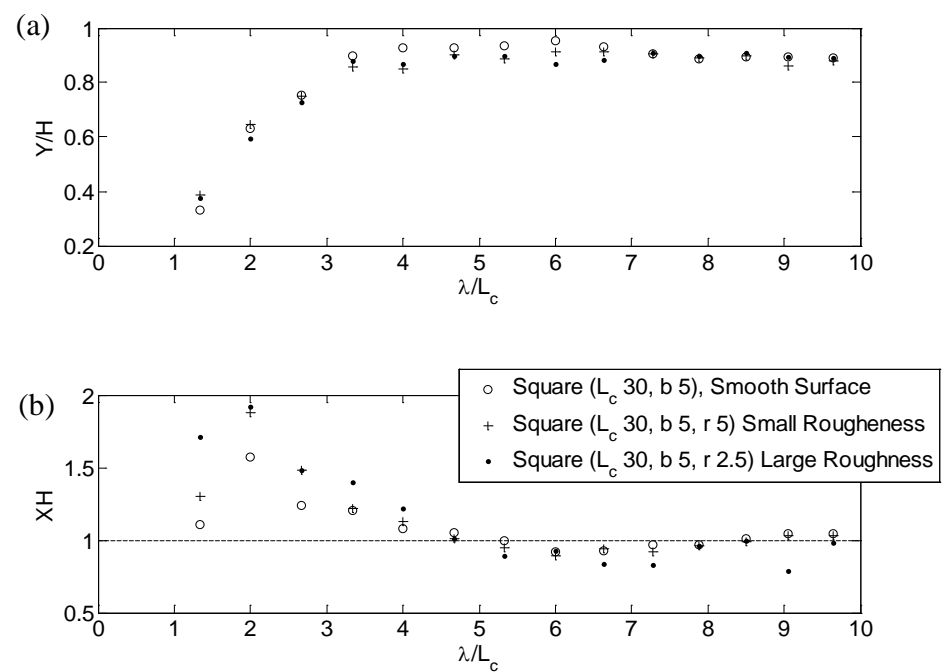

Figure 6. The heave (a) and surge (b) RAOs for the smooth and roughened $L_{c}=30 \mathrm{~cm}$ squares. 


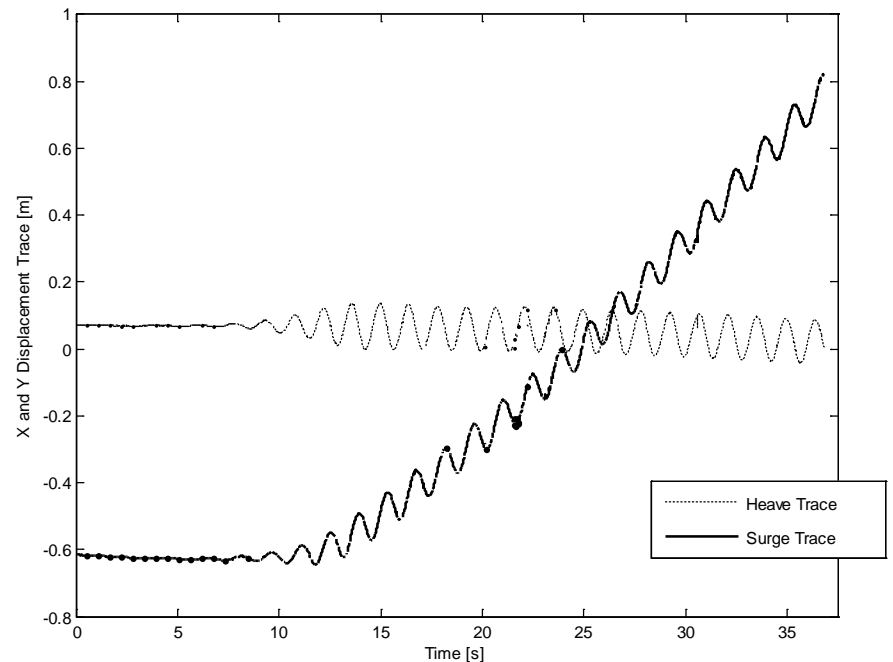

Figure 7. The time series X (surge: heavy black line) and Y (heave: light black line) trace for the surface centroid of square $\left(L_{c} 30, b 5\right)$ in regular waves of $\lambda=300 \mathrm{~cm}$ and $H=14.8 \mathrm{~cm}$.

(a)

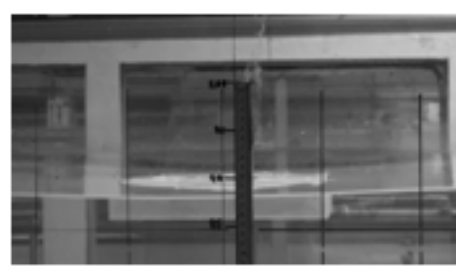

(d)

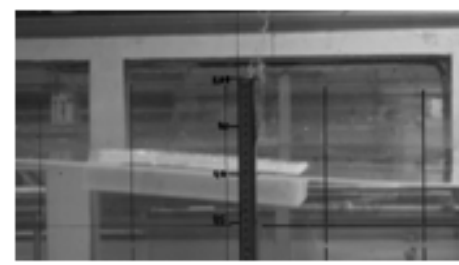

(b)

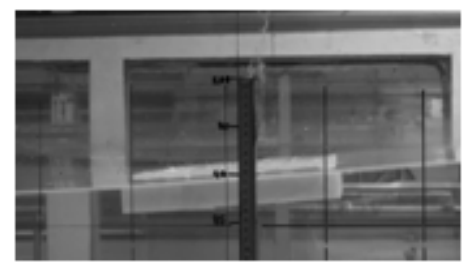

(c)

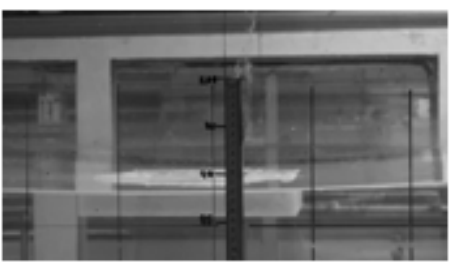

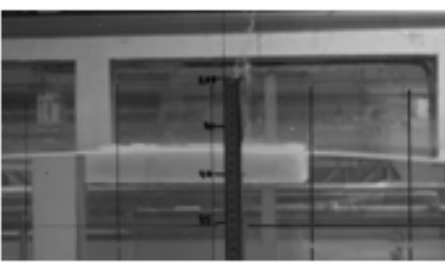

(f)

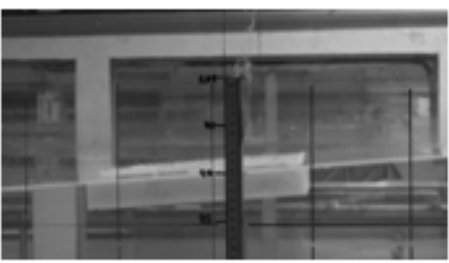

Figure 8. (a-f) A selection of video stills taken over one wave period of square $\left(L_{c} 30, b 5\right)$ in regular waves of $\lambda=180 \mathrm{~cm}$ and $H=5 \mathrm{~cm}$. 
(a)

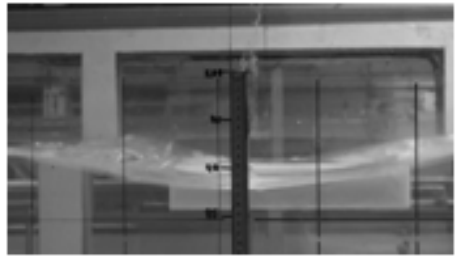

(b)



(c)

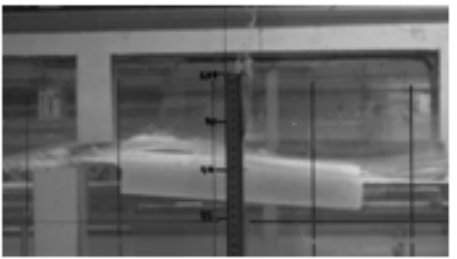

(d)

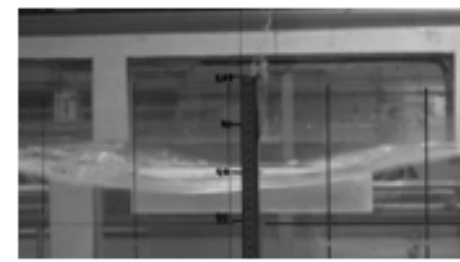

Figure 9. (a-d) A selection of video stills taken over one wave period of square $\left(L_{c} 30, b 5\right)$ in regular waves of $\lambda=40 \mathrm{~cm}$ and $H=5 \mathrm{~cm}$
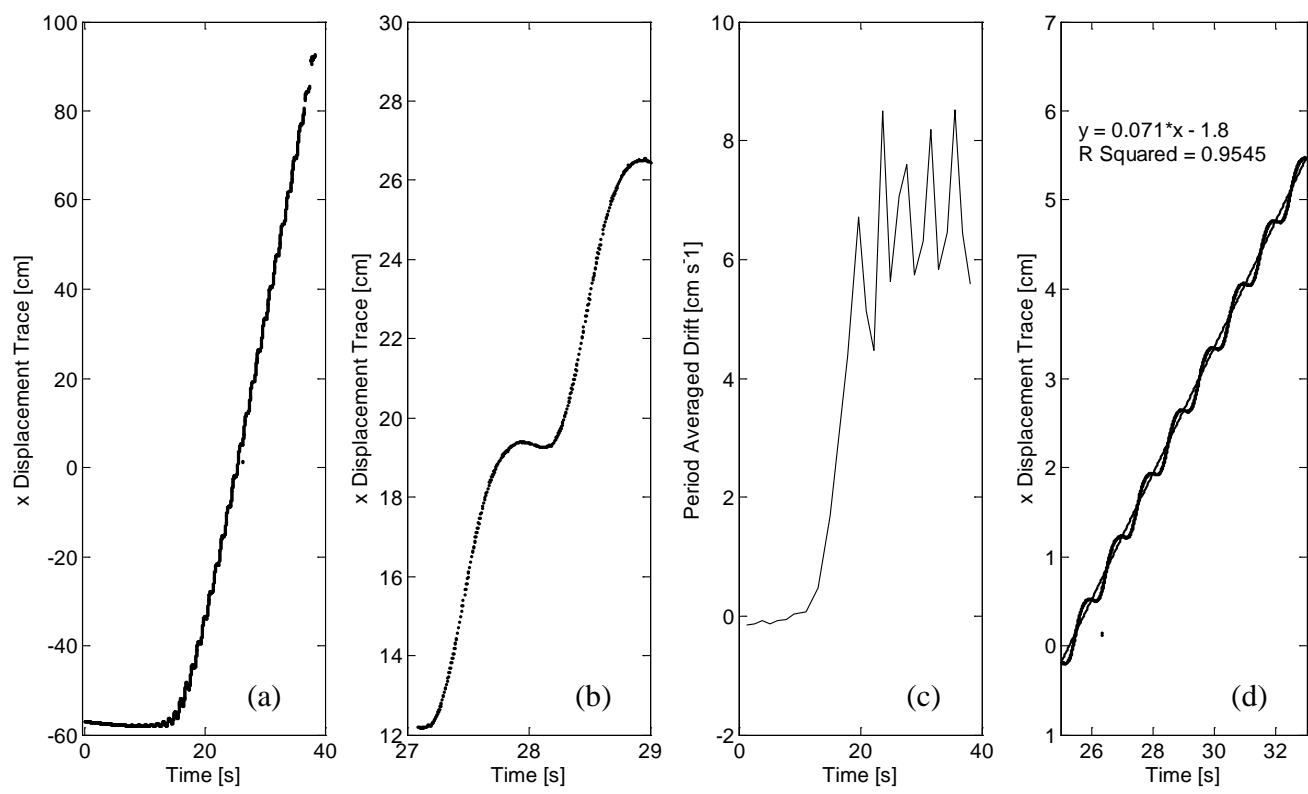

Figure 10. For square $\left(L_{c} 30, b 5\right)$ in regular waves of $T=0.947 \mathrm{~s}$ and $\lambda=140 \mathrm{~cm}$ : (a) time-series $x$ trace for surge motion; (b) segment of time series showing two cycles; (c) peak averaging method of calculating drift velocity and (d) the linear regression method. 

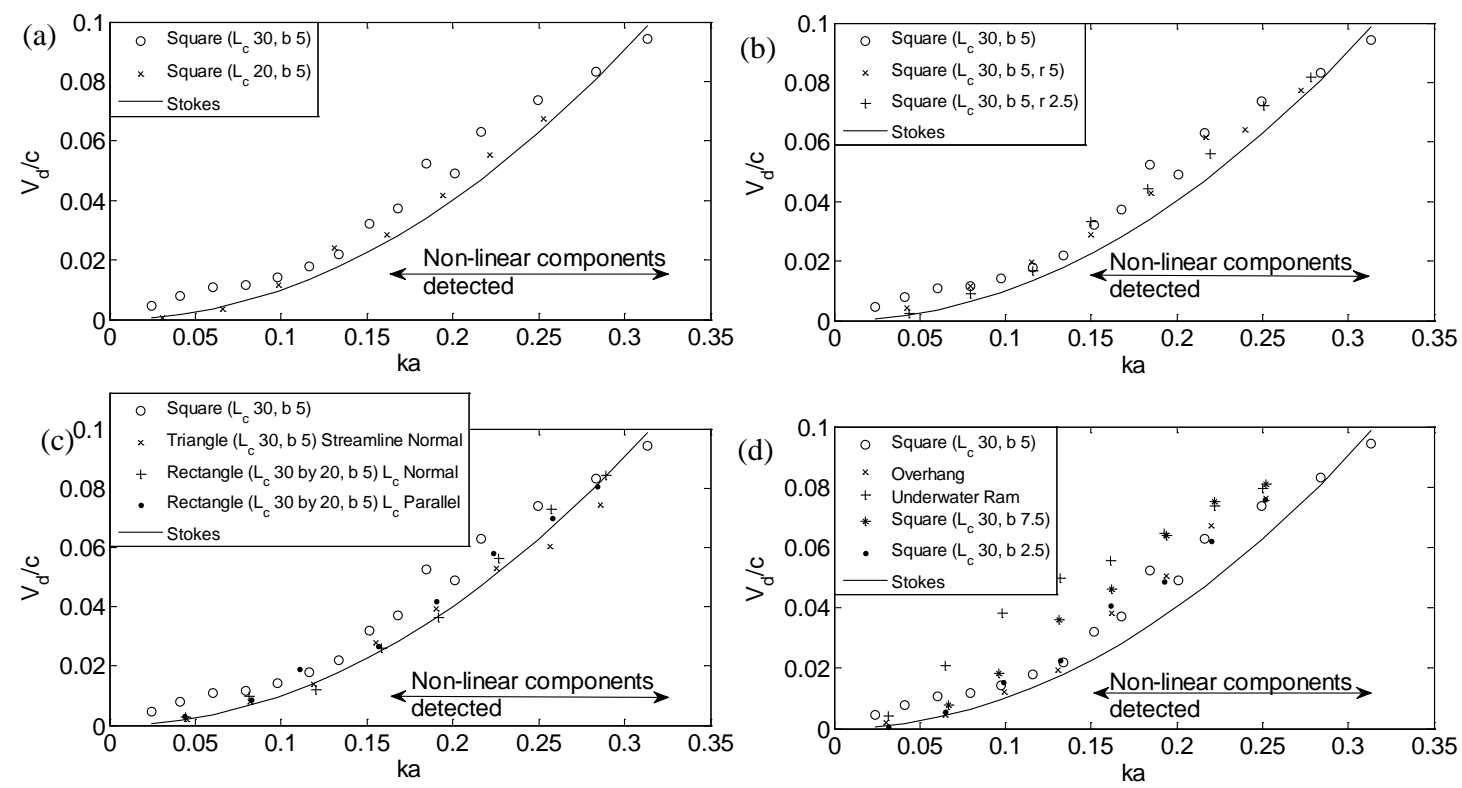

Figure 11a-d. Plots of $V_{d} / c$ as a function of wave steepness for several different floe models.
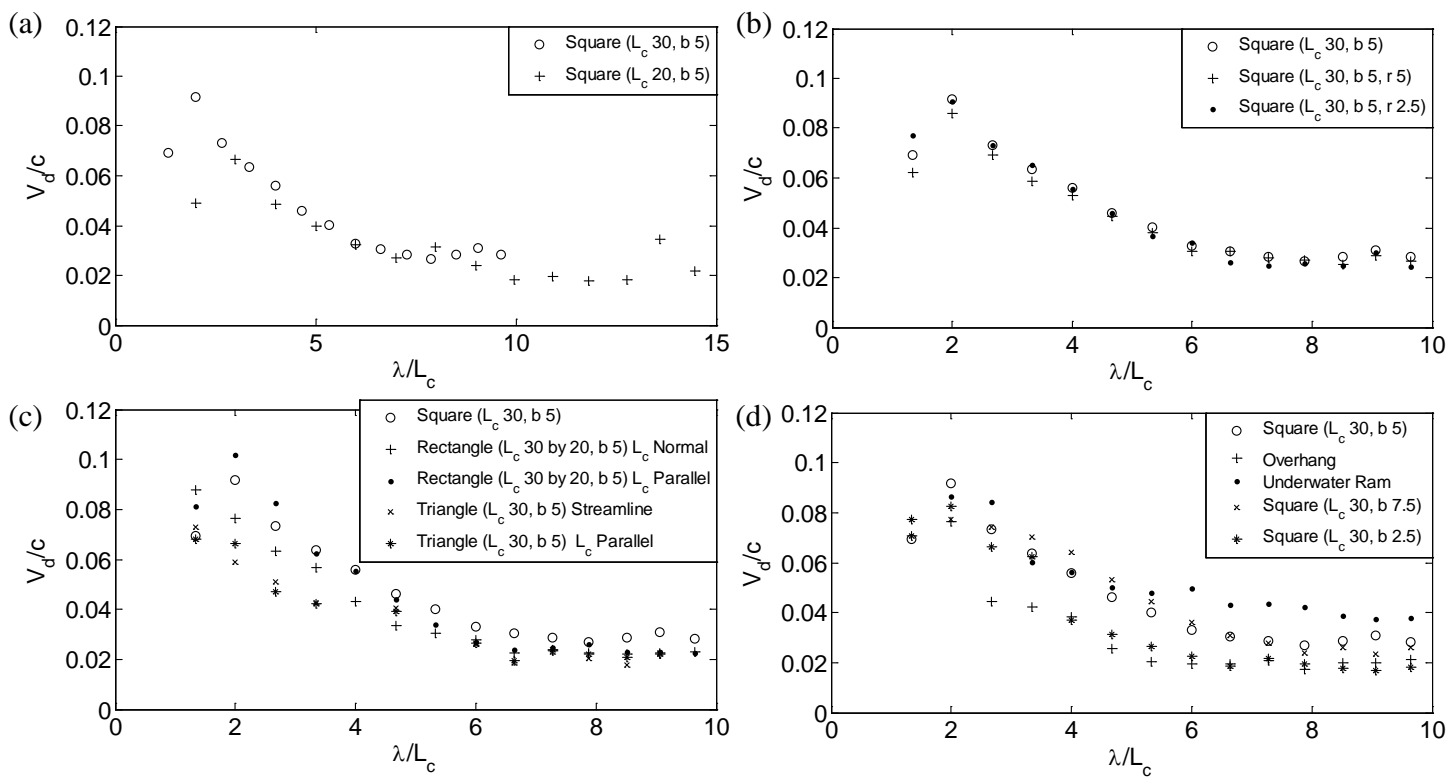

Figure 12a-d. Plots of drift velocity as a function of relative length for several different floe models. 


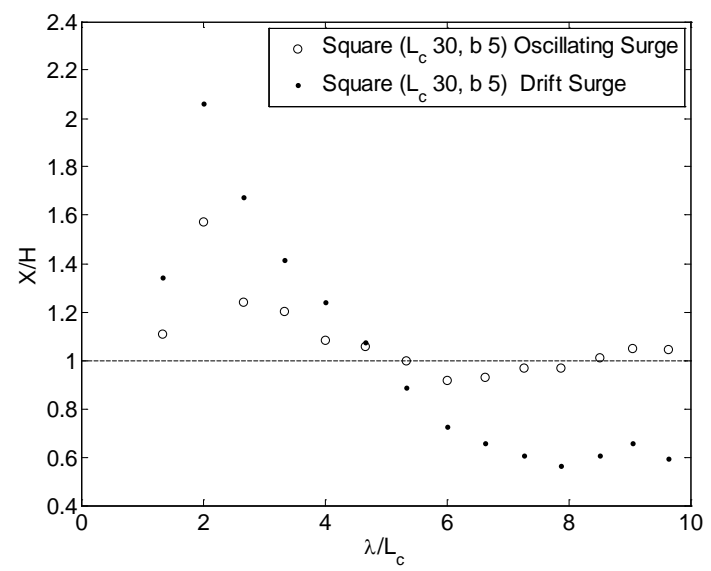

Figure 13. The oscillating and period-averaged drift surge components of the longitudinal motion of the square $\left(L_{c} 30, b 5\right)$ floe model as a function of $\lambda / L_{c}$.

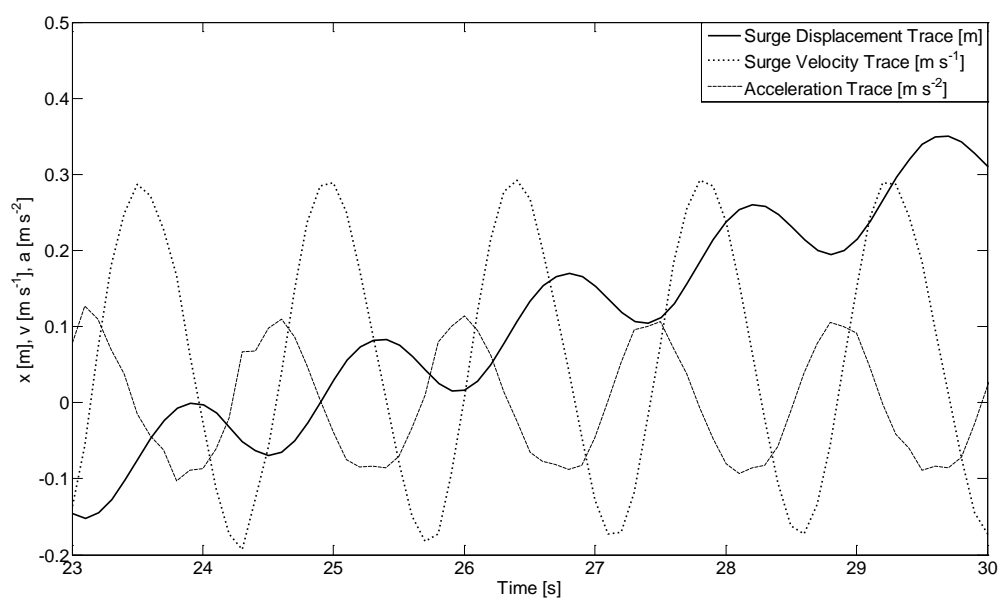

Figure 14. Time series displacement, velocity and accelerations during the quasi-steady state period of square $\left(L_{c} 30, b 5\right)$ at $\mathrm{T}$ $=1.389 \mathrm{~s}, \lambda=290 \mathrm{~cm}$ and $\mathrm{H}=14.81 \mathrm{~cm}$. 


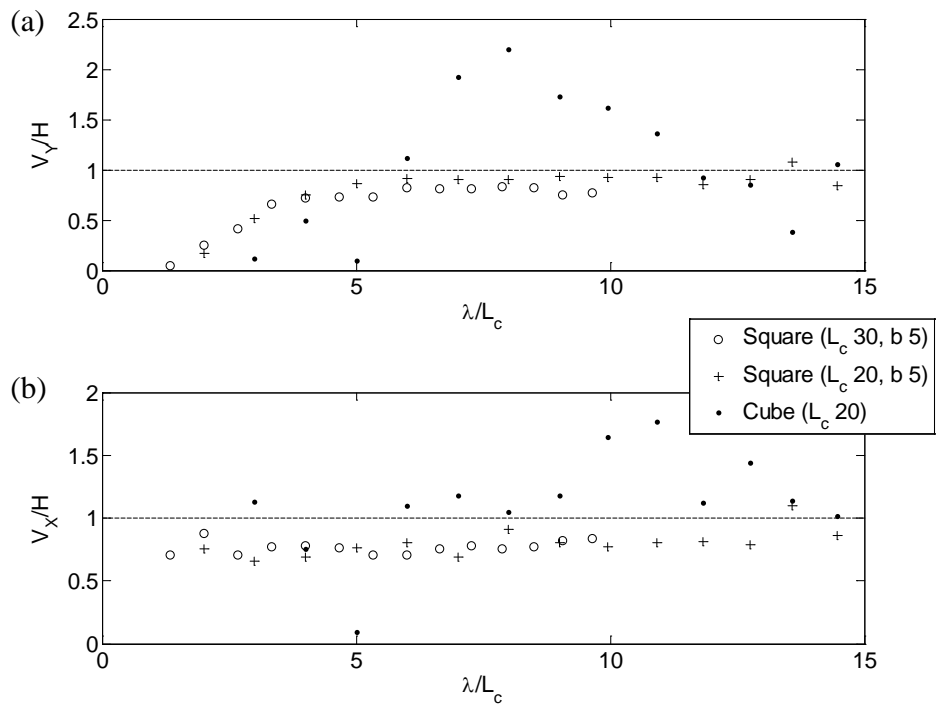

Figure 15. The heave (a) and surge (b) velocity normalised with theoretical particle velocity for square ( $\left.L_{c} 30, b 5\right)$, square $\left(L_{c}\right.$ $20, b 5)$ and cube $\left(L_{c} 20\right)$.

(a)

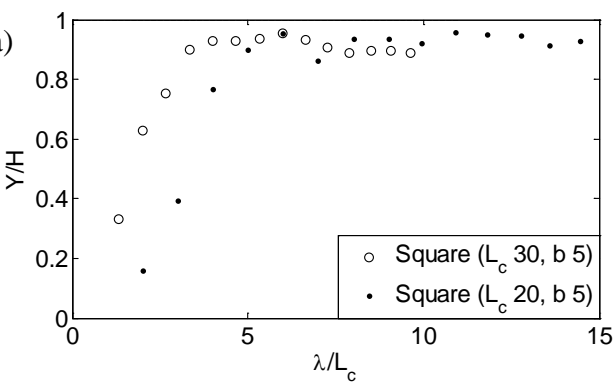

(c)

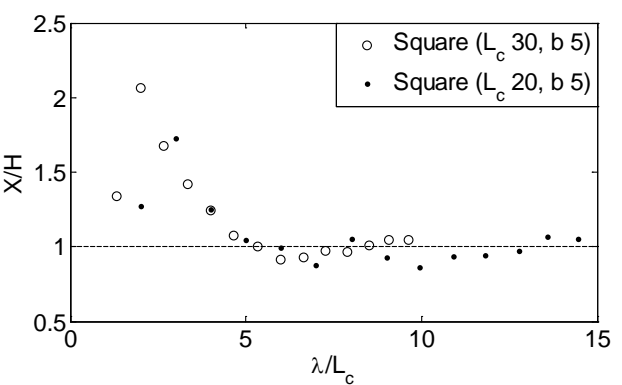

(b)
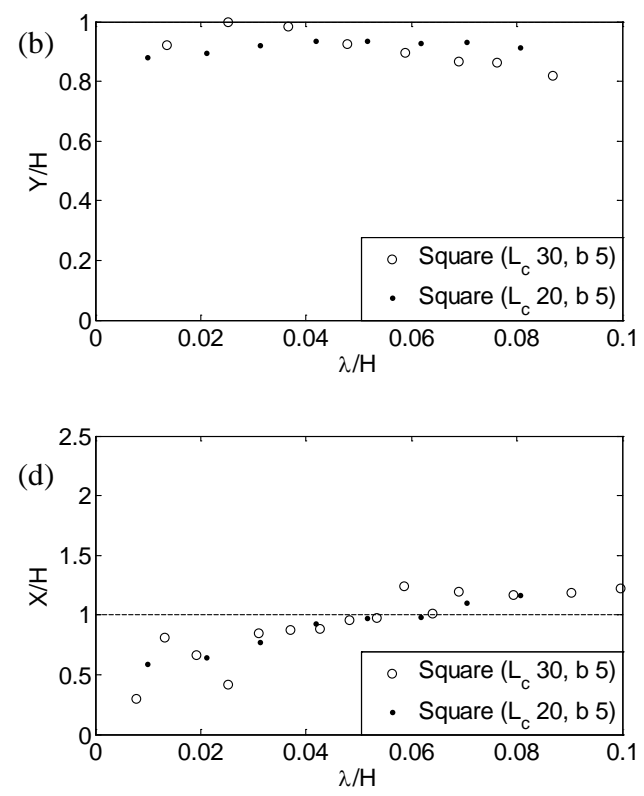

Figure 16. The heave (a, b) and surge (c, d) RAO of square $\left(L_{c} 30, b 5\right)$ and square $\left(L_{c} 20, b 5\right)$ as a function of relative length (a, c) and wave steepness (b, d). 
(a)

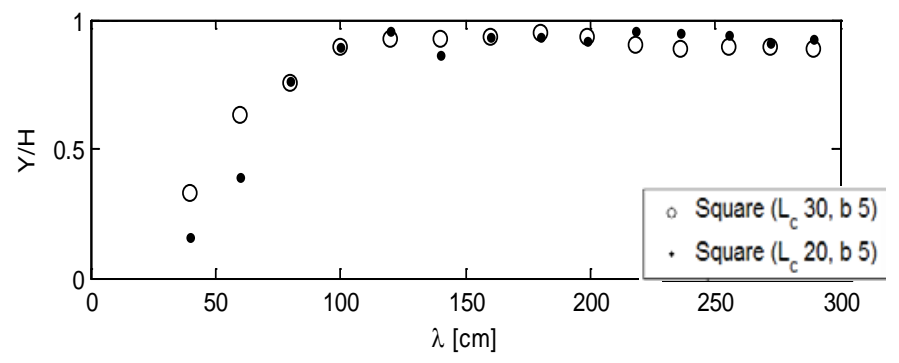

(b)

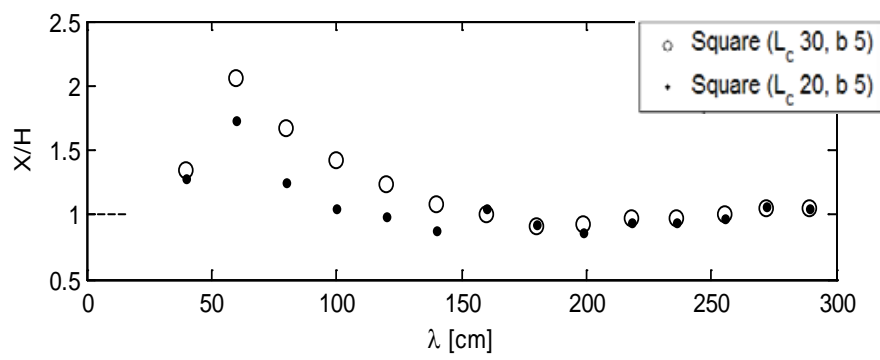

Figure 17. Heave (a) and Surge (b) RAO as a function of $\lambda$.

(a)

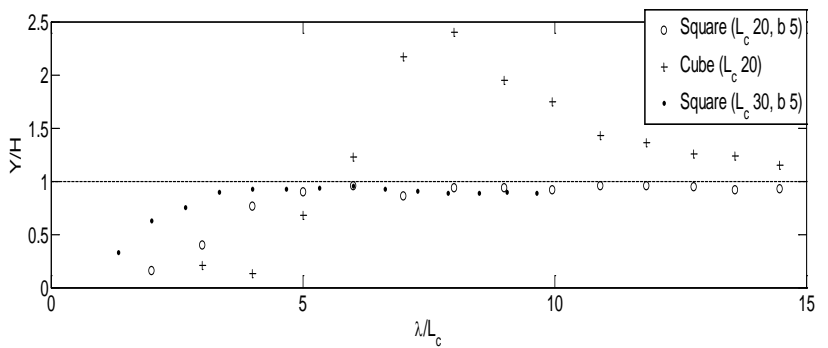

(b)

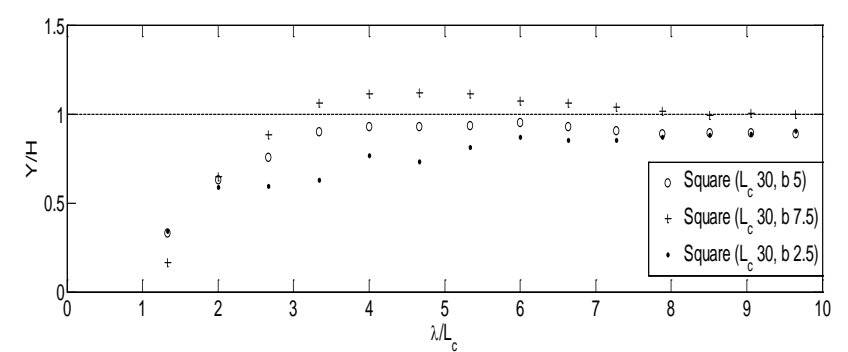

Figure 18. The heave RAO of square $\left(L_{c} 30, b 5\right)$, cube $\left(L_{c} 20\right)$, square $\left(L_{c} 20, b 5\right)$, (a) and square $\left(L_{c} 30, b 7.5\right)$, square $\left(L_{c}\right.$ $30, b 2.5)$, (b). 
(a)

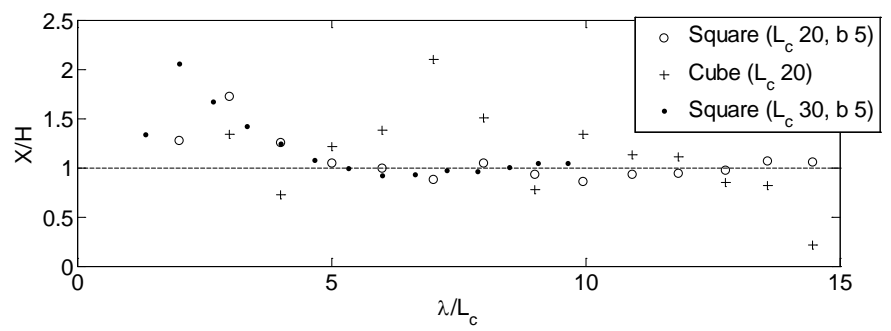

(b)

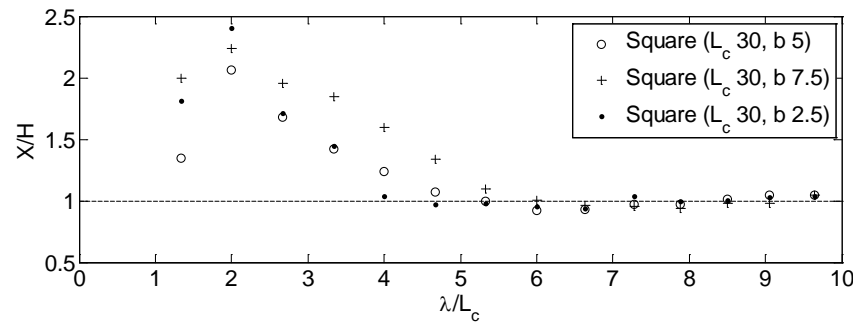

Figure 19. The surge RAO of square $\left(L_{c} 30, b 5\right)$, cube $\left(L_{c} 20\right)$, square $\left(L_{c} 20, b 5\right)$, (a) and square $\left(L_{c} 30, b 7.5\right)$, square $\left(L_{c} 30\right.$, b 2.5), (b).

(a)

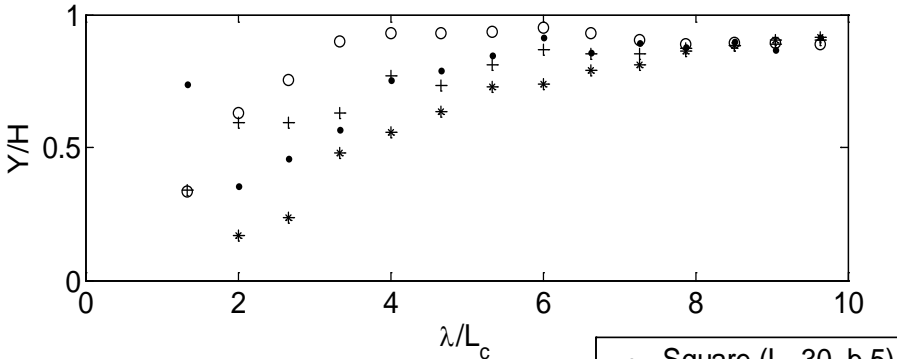

(b)

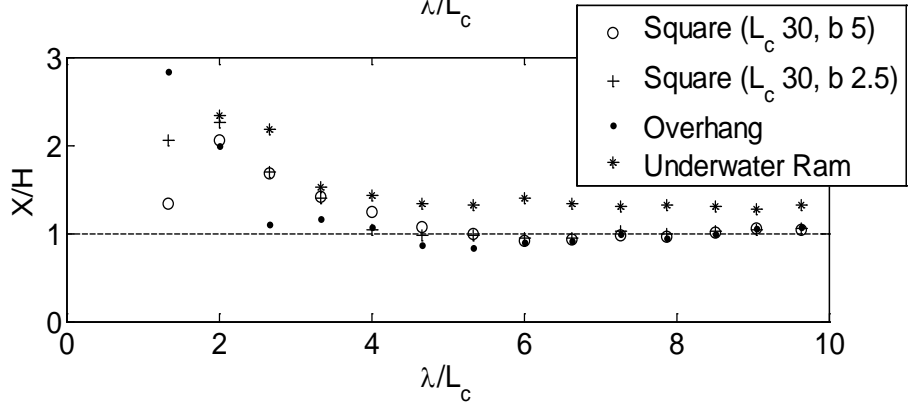

Figure 20. The heave (a) and Surge (b) RAO of square $\left(L_{c} 30, b 5\right)$, square ( $\left.L_{c} 30, b 2.5\right)$, overhang and underwater ram respectively. 


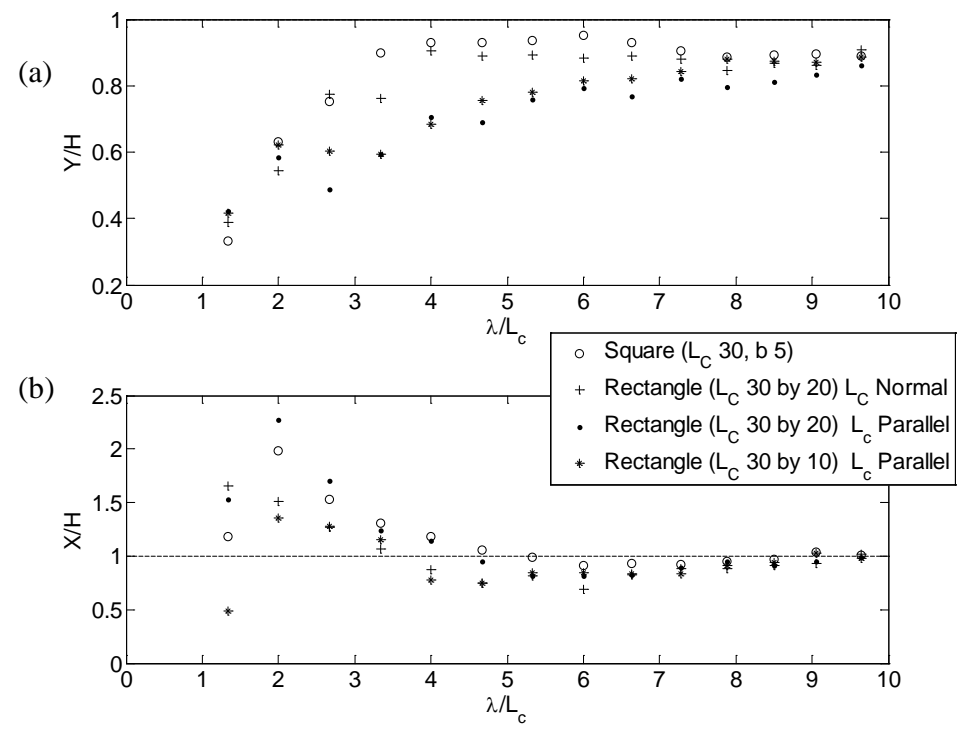

Figure 21. Heave (a) and Surge (b) RAO as a function of relative length for square $\left(L_{c} 30, b 5\right)$, rectangle $\left(L_{c} 30\right.$ by $\left.20, b 5\right)$ and rectangle ( $L_{c} 30$ by $10, b$ ) floe models.

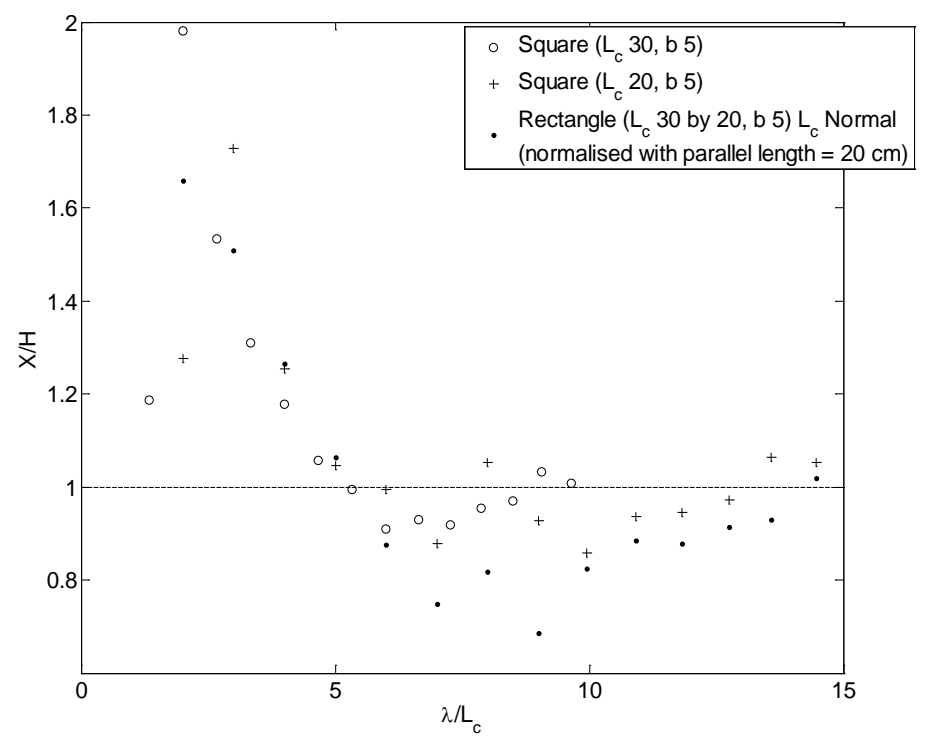

Figure 22. Heave and Surge RAO as a function of relative length for square $\left(L_{c} 30, b 5\right)$, rectangle $\left(L_{c} 30\right.$ by $\left.20, b 5\right)$ and rectangle ( $L_{c} 30$ by $\left.10, b 5\right)$ floe models. 
(a)

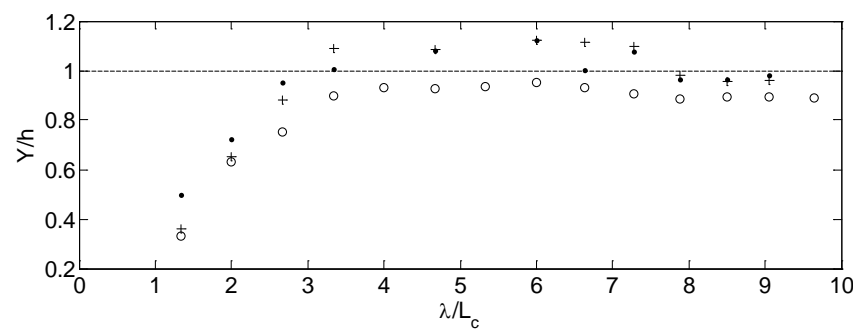

(b)

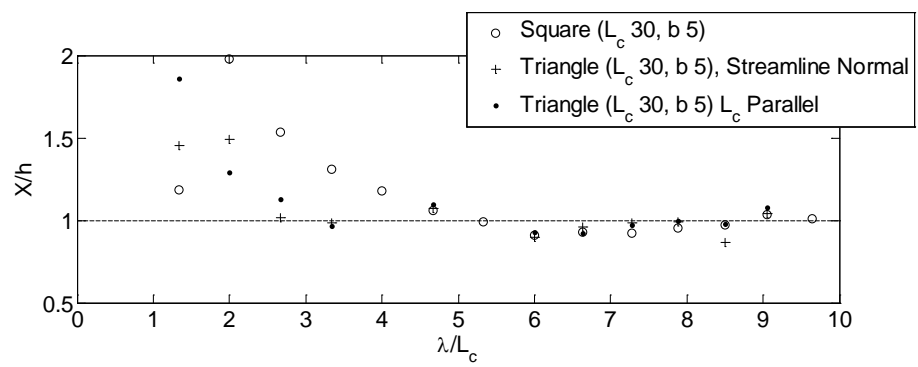

Figure 23. The heave (a) and surge (b) RAO of square ( $\left.L_{c} 30, b 5\right)$, triangle $\left(L_{c} 30, b 5\right)$ (streamline normal) and triangle ( $L_{c}$ $30, b 5), L_{c}$ parallel. 
Table 1. Ice floe model details.

\begin{tabular}{|c|c|c|c|}
\hline Model Name & Roughness & $L_{c}[\mathrm{~m}]$ & Length, width, thickness [m] \\
\hline Square $\left(L_{c} 30, b 5\right)$ & Smooth & 0.3 & $0.3 \times 0.3 \times 0.05$ \\
\hline Square $\left(L_{c} 30, b 5, r 5\right)$ & $0.6 \times 0.6 \mathrm{~mm}$ diameter holes every $0.05 \mathrm{~m}$ & 0.3 & $0.3 \times 0.3 \times 0.05$ \\
\hline Square $\left(L_{c} 30, b 5, r 2.5\right)$ & $0.6 \times 0.6 \mathrm{~mm}$ diameter holes every $0.025 \mathrm{~m}$ & 0.3 & $0.3 \times 0.3 \times 0.05$ \\
\hline Square $\left(L_{c} 20, b 5\right)$ & Smooth & 0.2 & $0.2 \times 0.2 \times 0.05$ \\
\hline Rectangle $\left(L_{c} 30\right.$ by 20, $b$ 5) & Smooth & 0.3 & $0.3 \times 0.2 \times 0.05$ \\
\hline Triangle $\left(L_{c} 30, b 5\right)$ & Smooth & 0.3 & $0.3 \times 0.3 \times 0.3 \times 0.05$ \\
\hline Square $\left(L_{c} 30, b 7.5\right)$ & Smooth & 0.3 & $0.3 \times 0.3 \times 0.075$ \\
\hline Square $\left(L_{c} 30, b 2.5\right)$ & Smooth & 0.3 & $0.3 \times 0.3 \times 0.025$ \\
\hline Overhang & Smooth & 0.3 & $0.3 \times 0.3 \times 0.025$ over $0.2 \times 0.2 \times 0.025$ \\
\hline Underwater Ram & Smooth & 0.3 & $0.2 \times 0.2 \times 0.025$ over $0.3 \times 0.3 \times 0.025$ \\
\hline Cube $\left(L_{c} 20\right)$ & Smooth & 0.2 & $0.2 \times 0.2 \times 0.2$ \\
\hline Rectangle $\left(L_{c} 30\right.$ by 10, $\left.b 5\right)$ & Smooth & 0.3 & $0.3 \times 0.1 \times 0.05$ \\
\hline Square $\left(L_{c} 24, b 4\right)$ & Smooth & 0.24 & $0.24 \times 0.24 \times 0.04$ \\
\hline Square $\left(L_{c} 20, b 3.3\right)$ & Smooth & 0.2 & $0.2 \times 0.2 \times 0.033$ \\
\hline
\end{tabular}


Table 2. Regular wave test conditions.

\begin{tabular}{|c|c|c|c|c|c|c|}
\hline Run & $\lambda[\mathrm{m}]$ & $T[\mathrm{~S}]$ & $F[\mathrm{~Hz}]$ & $H[\mathrm{~cm}]$ & $H / \lambda$ & $\lambda / L c$ \\
\hline VH16 & 180 & 1.07 & 0.93 & 16.0 & 0.09 & 0.167 \\
\hline VH14 & 180 & 1.07 & 0.93 & 14.0 & 0.08 & 0.167 \\
\hline VH12 & 180 & 1.07 & 0.93 & 12.0 & 0.07 & 0.167 \\
\hline VH10 & 180 & 1.07 & 0.93 & 10.0 & 0.06 & 0.167 \\
\hline VH8 & 180 & 1.07 & 0.93 & 8.0 & 0.04 & 0.167 \\
\hline VH6 & 180 & 1.07 & 0.93 & 6.0 & 0.03 & 0.167 \\
\hline VH4 & 180 & 1.07 & 0.93 & 4.0 & 0.02 & 0.167 \\
\hline VH2 & 180 & 1.07 & 0.93 & 2.0 & 0.01 & 0.167 \\
\hline VL300 & 290 & 1.39 & 0.72 & 13.4 & 0.04 & 0.100 \\
\hline VL280 & 270 & 1.34 & 0.75 & 12.4 & 0.04 & 0.107 \\
\hline VL260 & 255 & 1.29 & 0.77 & 11.6 & 0.04 & 0.115 \\
\hline VL240 & 236 & 1.24 & 0.81 & 10.7 & 0.04 & 0.125 \\
\hline VL220 & 218 & 1.19 & 0.84 & 9.8 & 0.04 & 0.136 \\
\hline VL200 & 199 & 1.13 & 0.88 & 8.9 & 0.04 & 0.150 \\
\hline VL180 & 180 & 1.07 & 0.93 & 8.0 & 0.04 & 0.167 \\
\hline VL160 & 160 & 1.01 & 0.99 & 7.1 & 0.04 & 0.188 \\
\hline VL140 & 140 & 0.95 & 1.06 & 6.2 & 0.04 & 0.214 \\
\hline VL120 & 120 & 0.88 & 1.14 & 5.3 & 0.04 & 0.250 \\
\hline VL100 & 100 & 0.8 & 1.25 & 4.4 & 0.04 & 0.300 \\
\hline VL80 & 80 & 0.72 & 1.4 & 3.6 & 0.04 & 0.375 \\
\hline VL60 & 60 & 0.62 & 1.61 & 2.7 & 0.04 & 0.500 \\
\hline VL40 & 40 & 0.51 & 1.97 & 1.8 & 0.04 & 0.750 \\
\hline
\end{tabular}

Table 3. The mean roll angle in degrees and sway in meter over the range of wave steepness for the floes plotted in Figure 11.

\begin{tabular}{|c|c|c|}
\hline Floe & $\begin{array}{c}\text { Mean Roll } \\
\text { Angle }\left[{ }^{\circ}\right]\end{array}$ & $\begin{array}{c}\text { Mean Sway } \\
{[\mathrm{m}]}\end{array}$ \\
\hline Square $(L c$ 30, $b$ 5) & 0.008 & 0.018 \\
\hline Square $(L c$ 30, $b 5, r$ 5) & 0.126 & 0.012 \\
\hline Square $(L c$ 30, $b 5, r$ 2.5) & 0.138 & 0.016 \\
\hline Square $(L c$ 20, $b$ 5) & 0.056 & 0.002 \\
\hline Rectangle $(L c$ 30 by 20, $b$ 5) $L c$ Normal & 0.054 & 0.002 \\
\hline Rectangle $(L c$ 30 by 20, $b$ 5) $L c$ Parallel & 1.125 & 0.002 \\
\hline Triangle $(L c$ 30, $b$ 5) & 1.065 & 0.011 \\
\hline Square $(L c$ 30, $b$ 7.5) & 0.041 & 0.001 \\
\hline Square $(L c$ 30, $b$ 2.5) & 0.043 & 0.015 \\
\hline Overhang & 1.118 & 0.005 \\
\hline Underwater Ram & 0.051 & 0.008 \\
\hline
\end{tabular}


Table 4. The heave and surge velocities and accelerations for selected models at selected $T$ and $\lambda$, along with extrapolated prototype values.

\begin{tabular}{|c|c|c|c|c|c|c|c|c|c|}
\hline Floe Name & $\lambda[\mathrm{m}]$ & $H[\mathrm{~m}]$ & $V_{X}\left[\mathrm{~m} \mathrm{~s}^{-1}\right]$ & $V_{Y}\left[\mathrm{~m} \mathrm{~s}^{-1}\right]$ & $A_{X}\left[\mathrm{~m} \mathrm{~s}^{-2}\right]$ & $A_{Y}\left[\mathrm{~m} \mathrm{~s}^{-2}\right]$ & $V_{X} / X_{P}$ & $V_{y} / Y_{P}$ & $E[J]$ \\
\hline Square $\left(L_{c} 30, b 5\right)$ & 2.89 & 0.148 & 0.29 & 0.3 & 0.1 & 0.14 & 0.82 & 0.89 & 0.17 \\
\hline Prototype & 289 & 14.8 & 2.87 & 2.99 & 0.1 & 0.14 & 0.82 & 0.89 & $1.7 \mathrm{E}+07$ \\
\hline Square $\left(L_{c} 30, b 5\right)$ & 1.99 & 0.096 & 0.18 & 0.22 & 0.08 & 0.12 & 0.67 & 0.82 & 0.07 \\
\hline Prototype & 199 & 9.6 & 1.81 & 2.18 & 0.08 & 0.12 & 0.67 & 0.82 & $6.7 \mathrm{E}+06$ \\
\hline Square $\left(L_{c} 30, b 5\right)$ & 1 & 0.048 & 0.15 & 0.13 & 0.05 & 0.09 & 0.78 & 0.71 & 0.04 \\
\hline Prototype & 100 & 4.8 & 1.46 & 1.33 & 0.05 & 0.09 & 0.78 & 0.71 & $4 \mathrm{E}+06$ \\
\hline Square $\left(L_{c} 30, b 7.5\right)$ & 2.89 & 0.133 & 0.27 & 0.29 & 0.11 & 0.14 & 0.86 & 0.97 & 0.15 \\
\hline Prototype & 289 & 13.3 & 2.69 & 2.93 & 0.11 & 0.14 & 0.86 & 0.97 & $1.5 \mathrm{E}+07$ \\
\hline Square $\left(L_{c} 30, b 7.5\right)$ & 1.99 & 0.085 & 0.18 & 0.23 & 0.07 & 0.12 & 0.76 & 0.77 & 0.07 \\
\hline Prototype & 199 & 8.5 & 1.8 & 2.26 & 0.07 & 0.12 & 0.76 & 0.77 & $6.7 \mathrm{E}+06$ \\
\hline Square $\left(L_{c} 30, b \quad 7.5\right)$ & 1 & 0.041 & 0.15 & 0.15 & 0.14 & 0.11 & 0.93 & 0.94 & 0.047 \\
\hline Prototype & 100 & 4.1 & 1.51 & 1.52 & 0.14 & 0.11 & 0.93 & 0.94 & $4.6 \mathrm{E}+06$ \\
\hline Underwater Ram & 2.89 & 0.12 & 0.31 & 0.25 & 0.1 & 0.11 & 1 & 0.86 & 0.19 \\
\hline Prototype & 289 & 12 & 3.08 & 2.54 & 0.1 & 0.11 & 1 & 0.86 & $1.9 \mathrm{E}+07$ \\
\hline Underwater Ram & 1.99 & 0.082 & 0.22 & 0.17 & 0.08 & 0.09 & 0.75 & 0.76 & 0.1 \\
\hline Prototype & 199 & 8.2 & 2.2 & 1.74 & 0.08 & 0.09 & 0.75 & 0.76 & $1.0 \mathrm{E}+06$ \\
\hline Underwater Ram & 1 & 0.041 & 0.02 & 0.06 & 0.04 & 0.05 & 0.11 & 0.38 & $6.4 \mathrm{E}-04$ \\
\hline Prototype & 100 & 4.1 & 0.18 & 0.62 & 0.04 & 0.05 & 0.11 & 0.38 & $6.4 \mathrm{E}+04$ \\
\hline
\end{tabular}

